ANUARIo DE Estudios MEDIEVAles (AEM)

$36 / 2$, julio diciembre de 2006

pp. 651-686

ISSN 0066-5061

\title{
«E VINGUEREN LOS OFFICIS E CONFRARIES $A B$ LLURS ENTREMESES E BALLS». UNA APROXIMACIÓN AL ESTAMENTO ARTESANAL EN LA BARCELONA BAJOMEDIEVAL, A PARTIR DEL ESTUDIO DE LAS CEREMONIAS DE ENTRADA REAL
}

\author{
Miguel RAUfast CHico \\ Institución Milá y Fontanals \\ CSIC, Barcelona
}

Resumen: Dos son los objetivos que confluyen en este artículo. Por un lado, mostrar hasta qué punto el estudio de las ceremonias colectivas urbanas, y en concreto de las entradas reales, en la Barcelona bajomedieval, es capaz de suministrar información útil para el conocimiento del estamento artesanal y de sus mecanismos asociativos. Al mismo tiempo, la atención sobre la participación de dicho estamento en las mencionadas ceremonias puede contribuir a dinamizar la visión, en ocasiones excesivamente escénica, que poseemos de dichos eventos.

Palabras clave: Oficios. Cofradías. Entrada real. Barcelona. Siglo XV.
Abstract: This article has two objectives. On the one hand, to show to what extent the study of collective urban ceremonies, and specifically royal entries, in Barcelona in the late Middle Ages, is able to furnish useful information for our knowledge of the artesan class and its associations. At the same time, focusing on the participation of the said class in the above mentioned ceremonies can help to make more vivid the image which we have of these events.

Keywords: Crafts. Guilds. Royal Entry. Barcelona. 15th Century.

\section{SUMARIO}

1. Introducción.- 2. ¿Oficios o cofradías?- 3. La participación del estamento artesanal en las ceremonias de entrada real.- 4. La visualización de una jerarquía: el desfile de los oficios. 4.1. Historia, fuentes y terminología. 4.2. Los oficios y cofradías en escena.- 5. El escenario tensionado: conflictos en torno a la participación y ordenación de los oficios en las ceremonias urbanas.- 5. Conclusión. 


\section{INTRODUCCIÓN ${ }^{1}$}

En un momento indeterminado de la segunda mitad del siglo XV, los calceteros de Barcelona decidieron expresar oficialmente a las autoridades municipales su malestar por el, a su juicio, agravio comparativo que sufría su oficio en relación a otras profesiones artesanales de la ciudad. En una articulada argumentación, reclamaban el derecho a poder disponer de representación política en el Consell de Cent, máximo órgano rector del municipio, tal y como correspondía, por privilegio real, a todo oficio que se desarrollase dentro del término territorial de la comunidad. Consideraban injustificado el ostracismo que pesaba sobre ellos, por cuanto no únicamente poseían cofradía propia y un número razonable de miembros, sino que, asimismo, habían venido significándose corporativamente «en entrades de rey e altres festes» promovidas a nivel institucional por la propia ciudad. Para los calceteros barceloneses, resultaba inadmisible, y en cierta forma incompatible, carecer de reconocimiento político dentro del municipio y que, al mismo tiempo, se reclamase su participación en aquellos actos públicos destinados, entre otras cosas, a reafirmar ceremonialmente la cohesión urbana e institucional de áquel: «E no sia digna cosa que un tant honrat offici e tants en nombre degen ésser obmesos e oblidats de les honors e útils de la dita ciutat, mas en aquelles ésser fets participants» ${ }^{2}$.

La protesta de los calceteros de Barcelona, interrelacionando oficio, cofradía, poder político y ceremonial urbano de una manera tan contundente como directa, parece confirmar en la práctica muchas de aquellas ideas o teorías esgrimidas en torno a una sociedad medieval "teatralizada", en la cual toda actividad pública requiere un cierto grado de dramatización ${ }^{3}$. Y puesto que lo que surge de las alegaciones esgrimidas por el oficio barcelonés es una triple presencia - política, social y escénica - susceptible de materializars en una misma $\operatorname{cosa}^{4}$, el documento en cuestión convida a sopesar en qué medida

${ }^{1}$ Este trabajo se inscribe en el marco del proyecto de investigación aprobado y financiado por la DGCYT: "Entre la Península Ibérica y el Mediterráneo. Interacciones políticas, económicas la doctora Roser Salicrú i Lluch.

Abreviaturas utilizadas: ACA = Archivo de la Corona de Aragón; AHCB = Archivo Histórico de la Ciudad de Barcelona; $\mathrm{BC}=$ Biblioteca de Cataluña; $\mathrm{C}=$ Cancillería; $\mathrm{CC}=$ Consell de Cent; CODOIN = Colección de Documentos Inéditos del Archivo de la Corona de Aragón; f. ff. = folio, folios; Ms = manuscrito; reg. = registro; $\mathrm{r}=$ recto; $\mathrm{v}=$ verso.

${ }^{2}$ AHCB, Fons gremial, 2A.2-4. Se trata de un documento suelto, sin datación alguna, pero con un encabezamiento de grafía posterior en el cual puede leerse: "1477. Calceteros». La imprecisión cronológica no puede, en todo caso, remontarse más allá de 1455, fecha de creación de la cofradía de los calceteros de Barcelona, ni ir mucho más lejos de finales del siglo XV, por desempeñando uno de los cinco puestos de conseller, cargo supremo en el gobierno de la ciudad.

${ }^{3}$ Véase, por ejemplo, Georges BALANDIER, El poder en escenas, Barcelona, 1994, pp. 36-37.

${ }^{4}$ En sintonía con lo ya expuesto por Mervin James en relación con la presencia de los oficios artesanales de la Inglaterra bajomedieval en la procesión del Corpus: "For the full expression of play cicle, as well as its place in the procession. This was true in a very concrete and practical, as well as symbolic kind of way» [Mervin JAMES, Ritual, Drama and Social Body in the Late Medieval English Town, "Past and Present", 98 (1983), p. 16]. 
a través de lo "teatral" puede avanzarse en el conocimiento del resto de factores.

A lo largo de todo el siglo XV y, por lo que sabemos, también de una parte del XIV, los oficios artesanales de Barcelona participaron activamente en aquellas ceremonias que, como la procesión de la fiesta del Corpus o la primera entrada del monarca en la ciudad, acabaron convirtiéndose en señas distintivas del municipio, en la medida en que tendían a implicar al conjunto de la población - particularmente al conjunto de estamentos urbanos con representación política: ciudadanos honrados, mercaderes, artistas (notarios, apotecarios y médicos, entre los más señalados) y artesanos- y ponían en juego el honor y el prestigio de la ciudad ${ }^{5}$.

La importancia del papel representado por los oficios artesanales en el contexto celebrativo de la Barcelona bajomedieval, así como la especial incidencia escénica asumida por éstos, es especialmente rastreable cuando se estudian las ceremonias de entrada real. Tanto los registros archivísticos municipales ${ }^{6}$ como los dietarios de la época ${ }^{7}$ son testimonios constantes de la estrecha asociación establecida entre la primera visita del monarca - pero también de la reina y del primogénito al trono- a la ciudad y el desfile de los oficios artesanales con el que el municipio expresaba su reconocimiento a la figura real.

«E vingueren los officis e confraries ab llurs entremeses e balls». Ésta es la expresión que utiliza el Manual de Novells Ardits - y que hemos querido tomar prestada para encabezar este artículo- a la hora de referirse a la contribución del estamento artesanal a la celebración de la entrada real de Juan

\footnotetext{
${ }^{5}$ Un aspecto claramente explicitado en la mencionada carta de los calceteros a los consellers de Barcelona: «E en entrades de rey e altres festes e empres que la dita ciutat faça, ab lur panó fan honor a la dita ciutat, axí bé com los altres officis e confraries» (AHCB, Fons gremial, 2A.24).

${ }^{6}$ Dentro del subfondo Consell de Cent del AHCB, las series Deliberacions, Ordenacions y Clavaria proporcionan una valiosa información sobre los preparativos, disposiciones y gastos, respectivamente, que acompañan la solemnización festiva de la entrada del rey en Barcelona a lo largo del siglo XV los oficios de la ciudad.

${ }^{7}$ Tanto el Manual de Novells Ardits, vulgarment apellat Dietari del Antich Consell Barceloní, 28 vols , Barcelona, 1892-1992 (en concreto los tres primeros volúmenes para el período entre 1390 y 1 '533), como el Dietari de la Deputació del General de Cathalunya, CODOIN, vols. XLVI y XLIX, Barcelona, 1974 y 1977 (o su edición actualizada en Josep Maria SANS I TRAVÉ, Dietaris de la Generalitat de Catalunya, vol. 1, Barcelona, 1994), para los años que van desde 1411 hasta 1512 , recogen, no siempre con idéntico detalle, los actos con los que la ciudad de Barcelona celebraba la llegada del monarca, siendo uno de ellos el tradicional desfile de los oficios con acompañamiento de representaciones y bailes. Igualmente, el Dietari o Llibre de Jornades (14111484) de Jaume Safont (edición de Josep Maria SANS I TRAVÉ), Barcelona, 1992), en esencia una duplicación del contenido del Dietari de la Deputació, es capaz, sin embargo, de ofrecer, en duplicación del contenido del Dietari de la Deputació, es capaz, sin embargo, de ofrecer, en ocasiones, descripciones mucho más minuciosas de este tipo de eventos, como la que dedica, por ejemplo, a la entrada del rey Pedro de Portugal en 1464 y al desfile de oficios que tuvo lugar con tal motivo. Mención especial merece el Llibre de les Solemnitats de Barcelona (edición de Agust DURAN I SANPERE y Josep SANABRE), 2 vols., Barcelona, 1930-1947, destinado específicamente a regiștrar todas aquellas ceremonias (en especial entradas y exequias reales, pero también procesiones de Corpus o convocatorias de la hueste urbana) cuya importancia o significación reclamaban una mayor meticulosidad narrativa, y que ha conservado, para el período comprendido entre 1423 y 1564 , por lo que se refiere a la Edad Media e inicios de la Edad Moderna, algunas de las más precisas imágenes literarias que, en la actualidad, poseemos sobre los oficios en escena.
} 
I en Barcelona, en $1458^{8}$. Se trata de una fórmula que encontramos repetida, con determinadas variaciones, a lo largo de todo el siglo XV y que sugiere, dentro del redactado general de los textos en los que la hallamos, una clara causalidad entre el juramento del monarca - en el catafalco preparado a tal efecto- de las libertades y privilegios de la ciudad, y la inmediata puesta en marcha de los oficios que desfilaban ante él, en un movimiento que, en Barcelona, parecía activarse únicamente en ese exacto y preciso momento ${ }^{9}$. ¿Qué representa, en realidad, la destacada presencia escénica del estamento artesanal en esos "momentos privilegiados para una historia de la psicología social urbana" que, en palabras de Paulino Iradiel, son las entradas reales bajomedievales ${ }^{10}$ ? En un universo ritual y teatralizado de procesiones y ceremoniales, tanto cívicos como religiosos, que colabora poderosamente a sostener el orden social ${ }^{11}$ y que refuerza, con impactante efectismo visual, la jerarquización sobre la cual éste está basado ${ }^{12}$, ¿qué lectura ha de hacerse del desfile de oficios cruzando ante la figura del soberano? ¿Expresa el "patriotismo municipal ardiente" de los artesanos, tal como sostiene Pierre Bonnassi $^{13} \mathrm{o}$, por el contrario, la llamativa exhibición del estamento no es, en el fondo, otra cosa que la suma aparente de esfuerzos particulares identitarios, dirigidos a diferenciar, antes que a unir, cada oficio respecto del resto de participantes en el desfile ${ }^{14}$ ? ¿Se trata de un homenaje al monarca, al cual los oficios deben el privilegio que les permite asociarse corporativamente o, tal vez, de aprovechar la oportunidad para compensar, "teatralmente", la limitada capacidad de intervención política que el sector artesanal tiene en la ciudad? Finalmente, ¿son los oficios quienes verdaderamente desfilan o, más

${ }^{8}$ Manual de Novells Ardits, vol. II. p. 294.

${ }^{9} \mathrm{El}$ grado de conexión entre ambos gestos llegó a ser tan intenso que, en determinadas circunstancias, la utilización, por parte de la ciudad, del desfile artesanal, dio pie a altercados con la propia monarquía. Es lo que sucedió en 1460, al celébrar Barcelona la visita del príncipe de Viana, hijo de Juan II, como si se tratase del primogénito al trono de la Corona de Aragón, cuando el monarca aún no lo había reconocido como tal. La protesta real, aunque tardía, ordenaba que «no sia feta al dit príncep altra exhibició de honor e preheminència, sinó solament aquella que poria o deuria ésser feta a un altre infant fill nostre que no fos fill primogènit» (ACA, C, reg.
3409, f. 37v. 1460, abril, 13. Olite).

${ }^{10}$ Paulino IRADIEL, Corporaciones de oficio, acción política y sociedad civil en Valencia, en Cofradías gremios y solidaridades en la Europa Medieval (Actas de la XIX Semana de

${ }^{11}$ Claude GAUVARD, Le rituel, objet d'histoire, en Jean-Claude SCHMITT; Otto GERHARD (dirs.), Les tendances actuelles de l'historie du Moyen Age en France et en Allemagne, París, 003, p. 273.

${ }^{12}$ «...las procesiones de carácter festivo de la baja Edad Media eran mayoritariamente proposiciones o esbozos de un esquema social explicativo de la organizạción humana a las clases alejadas del poder. Por ello, en su misma composición reflejan la jerarquía existente en la sociedad, su organización interna, etc. El sitio, el lugar en la procesión se convertía en un y discurso procesional en la Valencia bajomedieval en Isabel MoLL (ed.), La vida quotidiana dins la perspectiva historica (III Jornades d'Estudis Històrics Locals, 1983), Palma de Mallorca, 1985 , p. 182 .

${ }^{13}$ Pierre BONNASSIE, La organización del trabajo en Barcelona a fines del siglo XV, Barcelona, 1975, p. 56.

${ }^{14}$ Benjamin R. MCREE, Unity or division? The Social Meaning of Guild Ceremony in Urban Communities, en Barbara A. HANAWALT; Kathryn L. REYERSON (eds.), City and Spectacle in Medieval Europe, Minneapolis, 1994, p. 195. 
bien, el peso del espectáculo recae en esas organizaciones que les proporcionan una estructura interna y les confieren una identidad externa que son las cofradías?

En cualquier caso, son cuestiones que, más allá de las posibles respuestas que puedan generar al respecto, tienden a evidenciar, por sí solas, tanto la complejidad inherente a toda sociedad urbana como la riqueza interpretativa que permite todo gesto o conjunto de gestos - como es el caso, sin ir más lejos, de una ceremonia de entrada real-que se desarrollen en su interior. Tras toda imagen de unidad social es factible intuir un cúmulo de fragmentaciones ${ }^{15}$, tensiones intensas ${ }^{16}$ y disonancias ${ }^{17}$ que, sin acabar de disgregar el conjunto, lo muestran en su exacta dimensión, incesantemente dinamizado por el juego entre iniciativas que quieren ser cohesionadoras y tendencias que no pueden evitar resultar disgregadoras. Igualmente, tras todo orden - como puede ser, en su sentido más literal, aquél que determina la colocación de cada oficio dentro de un desfile- es previsible detectar el pulso mantenido entre la privilegiada jerarquía de unos y las legítimas aspiraciones de otros ${ }^{18}$

El encuentro entre oficios y entradas reales medievales que este artículo plantea, incide, en cierta medida, en algunas de estas cuestiones. No se pretende aquí, ni mucho menos, abordar a fondo ninguno de los dos temas, suficientemente complejos como para eliminar toda tentación al respecto y, por lo que se refiere a la Barcelona bajomedieval, aún pendientes de adquirir un verdadero rango historiográfico - en el caso de las entradas reales- o reducidos a puntuales aportaciones mayormente ya lejanas en el tiempo - como sucede con el tema del artesanado. Se trata, en definitiva, de intentar establecer un puente de comunicación entre ambos temas que permita, un poco en la línea planteada por Antonio Ivan Pini en su trabajo sobre los oficios artesanales en la Italia septentrional medieva $1^{19}$, abrir nuevas posibilidades de investigación a la hora de estudiar tanto el artesanado medieval como aquellas manifestaciones escénicas en la que éste aparece implicado.

\footnotetext{
${ }^{15}$ Flocel SABATÉ, Lo senyor rei és mort!, Lleida, 1994, p. 227.

${ }^{16}$ "Conflict was the dark side of the moon of unity. However, without conflict, no social wholeness either» ( M. JAMES, Ritual, Drama, p. 8).

${ }^{17}$ Edward MuIr, Fiesta y rito en la Europa Moderna, Madrid, 2001, p. 289.

${ }^{18}$ Jacques HEERS, Fêtes, jeux et joutes dans les sociétés d'Occident à la fin du Moyen Âge, París, 1971, p. 22.

${ }^{19}$ «L'idea-base della ricerca era che, analizzando l'ordine con cui le singole arti si succedevano nelle solenni processioni, si poteva forse cogliere la gerarchia del loro prestigio sociale..." (Antonio Ivan PINI, Le arti in processione. Professioni, prestigio e potere nelle città stato dell'Italia padana medievale, en IDEM, Città, comuni e corporazioni nel medioevo italiano, Bolonia, 1986, p. 262).
} 


\section{2. ¿OFICIOS O COFRADÍAS?}

No es ninguna exageración afirmar que el análisis del asociacionismo profesional artesanal en la Barcelona medieval está aún por hacer ${ }^{20}$. Aunque resulta innegable la existencia de una cierta tradición historiográfica sobre el tema, materializada en la encomiable tarea recopiladora llevada a cabo por algunos historiadores entre el siglo XVIII e inicios del $\mathrm{XX}^{21}$, y en la aparición, a lo largo de esta última centuria, de un buen número de trabajos de marcado carácter específico ${ }^{22}$, lo cierto es que se sigue encontrando a faltar una ambiciosa obra de síntesis que unifique, en cierto sentido, la dispersión, un tanto inconexa, en la que parece moverse toda la producción anterior, y que dote al tema de un marco metodológico e interpretativo del que, por ahora, carece. Las obras de Pierre Bonnassie ${ }^{23}$ y de Robert Freitag ${ }^{24}$, que por objetivos y alcance de sus planteamientos se aproximarían a esta exigencia,

${ }^{20}$ Para un estado de la cuestión en el conjunto de la Cataluña bajomedieval, véase Antoni RIERA I MELIS, La aparición de las corporaciones de oficio en Cataluña (1200-1350), en Cofradías, gremios y solidaridades, pp. 286-292.

${ }^{21}$ Resulta obligado citar a Antonio de CAPMANY Memorias históricas sobre la marina, comercio y artes de la antigua ciudad de Barcelona, Madrid, 4 vols., 1779-1792; Francisco de BOFARULL, Gremios y cofradias de la antigua Corona de Aragón, COODOIN, vols. XL y XLI, Barcelona, 1876 y 1910; O Miquel GONZÁLEZ SUGRANYES, Contribució a la història dels antichs gremis dels Arts i Oficis de la ciutat de Barcelona, 2 vols., Barcelona, 1915-1918.

${ }^{22}$ Podemos mencionar, entre otros, a Aurelio CAPMANY, Historial del gremi de bastaixos de capçana $i$ macips de ribera de la duana de Barcelona. Segle XIII-XX, Barcelona, 1933; Josep Ma MADURELL I MARIMON, Les ordinacions de l'ofici de mestre de cases de Barcelona "Butleti del Centre Excursionista de Catalunya”, 47 (1937), pp. 231-238; Eduardo ASENSIO, El gremio de tejedores de Barcelona a finales del siglo XIV en VII Congreso de Historia de la Corona de Aragón, Barcelona, 1962, vol. II, pp. 407-416; Manuel RIU I RIU, Aportación a la organización gremial de la industria textil catalana en el siglo XV, en VII Congreso de Historia de la Corona de Aragón, vol. II, pp. 547-559; Joan-F. CABESTANY I FORT, Els mestres sabaters $i$ la confraria de Sant Marc (segle XIV), en Homenaje a Jaume Vicens Vives, 2 vols., Barcelona, 1967, vol. II, pp. 75-84. IDEM Confraries i gremis a Barcelona. Segles XIII a XVI' "Finestrelles" 2' (1990) pp. 141-145: Margarita TINTÓ I SALA, Els gremis a la Barcelona medieval, Barcelona, 1978: pADEM, La historia del gremi de serrallers i ferrers de Barcelona. Any 1380 , Barcelona, 1980; EADEM, Aportación al estudio de los gremios del siglo XV: los libros gremiales de Barcelona, en IX Congreso de Historia de la Corona de Aragón. Zaragoza, 1984, pp. 203-228; EADEM, Els tenders revenedors de la ciutat de Barcelona, Barcelona, 1991; EADEM, Ordinacions dels tenders revenedors de la ciutat de Barcelona, Barcelona, 1991; EADEM, Ordinacions dels barquers de la ciutat de Barcelona durant el segle XV, "Medievalia", 10 (1992) „pp. 413-424; EADEM, Les cases gremials de Barcelona i el seu entorn urbà "XVII Congrés d'Història de la Corona d'Aragón". Actes, vol. II, Barcelona, 2003, pp. 895-910; Philip BANKS, The origins of the "Gremi de Sabaters" of Barcelona, "Quaderns d'Arqueologia i Història de la Ciutat", 18
(1980), pp. 109-118; Carme BATLLE, Contribució a la història dels oficis de Barcelona: els (1980), pp 109-118; Carme BATLLE, Contribució a la història dels oficis de Barcelona: els carnicers del segle XIII, "Quaderns d'Estudis Medievals", II-1 (1981), pp. 310-318; José Luís
MARTÍN, "Ordinacions dels hostalers, taverners e aventurers» de Barcelona a fines del siglo XV, en Miscel lània en Homenatge al P. Agusti Altisent, Tarragona, 1991, pp. 73-93; Albert CUBELES I BONET, Els argenters $i$ el Consell de Cent en el segle XIV, en Joaquin YARZA; Francesc FITE (eds.), L'artista-artesà medieval a la Corona d'Arago, Lleida, 1999, pp. 343-364; Josep M. VILA ICARABASSA, La participació de l'estament artesanal en el Consell de la ciutat (segles XIII-XVI). l'exemple dels terrissers "Barcelona. Quaderns d'Història", 4 (2001), pp. 183-192; Ma Carmen RIU DE MARTÍN, El treball artesà a Barcelona als segles XIV al XVI segons les ordinacions gremials: els esparters $i$ vidriers, "Acta Historica et Archaeologica Mediaevalia", 23-24 (2002 oficios de la ciudad (carpinteros, zapateros, merceros, etc.) que se incluye en la obra de Agustí DURAN I SANPERE, Barcelona i la seva història, 3 vols., Barcelona, 1972.

${ }^{23} \mathrm{P}$. BONNASSIE, La organización del trabajo.

${ }^{24}$ Robert FREITAG, Die katalanischen Handwerkerorganisationen unter Königsschutz im Mittelalter: insbesondere Aufbau und Aufgaben im 14. Jarhhundert, "Spanische Forschungen der Görresgeselleschaft", 24 (1958), pp. 41-226. Incomprensiblemente, este trabajo sigue, hoy en día,
sin haber sido traducido en el Estado español. 
no cubren, ni mucho menos, todas las expectativas y, en consecuencia, tampoco pueden ser utilizadas como eximentes a la hora de profundizar en el estudio de la organización artesanal de la Barcelona bajomedieval ${ }^{25}$.

Las consecuencias directas derivadas de esta situación - que, por otra parte, no parece privativa del conjunto de Cataluña ${ }^{26}$ - se dejan notar con particular y negativa incidencia en todo aquello relacionado con el origen y la evolución de las formas organizativas artesanales. Y lo que es peor, a la incapacidad para diagnosticar con cierta precisión la relación, tanto sincrónica como diacrónica, entre dichas formas (es decir, y a grandes rasgos, entre corporación de oficio y cofradía), viene a unirse la indisimulable dificultad que, ya de hecho, provoca entre los historiadores el simple intento de identificarlas. Tal como ha señalado Antoni Riera, no existe una unanimidad contrastada respecto a la terminología a emplear en este campo de estudio ${ }^{27}$, y así, conceptos como "oficio", "cofradía" e, incluso "gremio"-que, strictus sensu, tan sólo es utilizable a partir de la Edad Moderna -, tan pronto parecen compartir significado como representar cosas absolutamente distintas, un tanto en función del énfasis dado por el investigador a una u otra de las finalidades atribuidas al asociacionismo artesanal, y en una clara muestra de la complejidad, aún no desvelada del todo, de este tipo de organizaciones profesionales.

No intentaremos entrar en dicha problemática - que excede en mucho tanto las posibilidades como el interés real de este artículo- y nos limitaremos aquí a esbozar mínimamente algunos aspectos relacionados con el tema que sí consideramos básicos para el desarrollo de nuestra investigación.

En 1257, Jaime I reestructuraba el gobierno municipal de Barcelona, estableciendo, junto a la figura de los consellers, un Consell general en el cual aparecían representados, además del patriciado y de los mercaderes, los oficios de la ciudad $^{28}$. La contribución del artesanado a dicha institución, se desglosaba de la siguiente manera:

${ }^{25}$ No ha de olvidarse que el trabajo de Bonnassie, aunque editado en España en 1975, apareció -como tesina de licenciatura- en 1955 y que, en realidad, se circunscribe a un período muy concreto de tiempo, como es el último cuarto del siglo XV. Por lo que respecta a la obra de Freitag, queda la duda de hasta qué punto, a causa de su edición únicamente en lengua alemana, ha podido tener repercusión entre los historiadores de nuestro país.

${ }^{26}$ Para el reino de Valencia, Manuel Benítez remarca el déficit de estudios sobre el tema existente hasta la fecha (Manuel BENÍTEZ BOLORINOS, Las cofradías medievales en el reino de Valencia (1329-1458), Alicante, 1998, p. 13). Por lo que se refiere a Castilla en concreto, y a la Península Ibérica en general, Denis Menjot considera que el sector artesanal continúa siendo «la catégorie sociale urbaine la moins connue» (Denis Mera que el sector artesanal continúa siendo "la catégorie sociale urbaine la moins connue» (Denis MENoT, Les métiers en Castille au Bas Moyen (eds.), Les métiers au Moyen Age. Aspects économiques et sociaux, Louvain-la-Neuve, 1994, p. 206).

${ }^{27}$ A. RIERA, La aparición de las corporaciones, p. 292.

${ }^{28}$ Acerca de la evolución institucional del Consell de Cent, véanse entre otros, Carme BATLLE, La crisis social y económica de Barcelona a mediados del siglo XV, 2 vols., Barcelona 1973, vol. I, en especial las pp. 65-80; Pere ORTí I GOST, El Consell de Cent durant l'Edat Mitjana, "Barcelona. Quaderns d'Història", 4 (2001), pp. 21-48. 
..9 pelayres, 9 pellejeros, 11 colchoneros, 4 freneros, 3 latoneros, 6 bolseros, 8 albarderos, 2 corazeros, 5 zapateros, 4 texedores de lino, 2 tintoreros, 3 sastres, 2 ballesteros, 4 herreros, 4 carpinteros, 2 alfareros, 4 toneleros, 3 cantareros, 4 algodoneros, 1 zurrador, 2 revendedores, 2 hortelanos, 2 corredores de encante ${ }^{29}$.

Se hace difícil de precisar con exactitud el grado y cualidad del reconocimiento que dicha disposición daba a entender. En cualquier caso, la distinción política de las profesiones artesanales sugería, indefectiblemente, una presencia social cuando menos notoria y plenamente asentada, acorde con una dinámica general de desarrollo económico urbano común a todo el Occidente medieval europeo ${ }^{30}$. Otra cosa es calibrar en qué medida los diferentes oficios convocados a la participación en el gobierno municipal de la ciudad representaban entidades con una elaborada organización corporativa - a diferencia de aquellos otros que, ausentes de dicha lista, supuestamente carecían de ella-, o si, por el contrario, se trataba únicamente de simples agrupaciones laborales que, por prestigio profesional o por el número de sus integrantes, merecían ser destacadas del resto y asumir un papel protagonista en el reparto de puestos dentro del Consell de Cent barcelonés ${ }^{31}$.

A lo largo de todo el siglo XIV y de la primera mitad del XV, tanto el Llibre del Consell como los registros de Deliberacions conservados en el AHCB nos permiten comprobar, gracias a las anotaciones periódicas en las que quedaba registrada la composición del Consell de Cent tras la correspondiente elección anual de sus nuevos miembros, cómo el estamento artesanal continúa manteniendo su presencia institucional, al mismo tiempo que nos

\footnotetext{
${ }^{29}$ Utilizamos aquí la lista que suministra A. de CAPMANY, Memorias històricas (reedición de 1963 en 3 vols.), vol. II, p. 915, y que también aparece reproducida en C. BATLLE, La crisis social y económica, vol. I, p. 73. Esta última autora se ha encargado de señalar que a pesar de que Capmany cita las Rubriques de Bruniquer (recopilación de datos procedentes del Archivo Histórico de la Ciudad de Barcelona realizada en el siglo XVII) como fuente de información, el dato en cuestión no aparece recogido en ellas, y, hasta la fecha, tampoco ha sido posible encontrar referencia archivística alguna que permita documentar la mencionada enumeración de oficios. En cualquier caso, el Memorial historic de Joan Francesc Boscà, obra del siglo XV, incluye una descripción similar de la aportación artesanal al Consell de Cent de 1257 que, a efectos comparativos, consideramos adecuado reproducir aquí: "...Pellicers, VIIII. Maellers, .XI. Ffreners, .IIII. Fivellers, .III. Corregers e bossers, .VI. Blanquers e albadiners, VIII. Cuyraçers, .II. Sabaters, .V. Teixidors, .IIIII. Tintorers, .II. Sastres, .III. Ballesters, .II. Ferrers, .IIII. Fusters e galotxers, .IIII. Perpunters, .II. Boters, IIII. Lamborders e molers, .III. Cotoners, .IIII Revenedors e calderers, .II. Ortolans, III. Adobadors, .I. Corredors, .II» (Joan Francesc BoSCÀ, Memorial históric Barcelona, 1977, p. 34). Puede encontrarse igualmente una comparación entre ambas listas en J.M.M. VILA, La participació de l'estament artesanal, p. 184.

${ }^{30}$ Recordemos que, ya en 1200 , en un privilegio de Paz y Tregua concedido por Pedro I a Barcelona, quedaba claramente explicitado el reconocimiento del sector artesanal: "Cavadors, e Lauradors, Pellicers, Sastres, Texidors, e tots Menestrals sots aquesta Pau, e seguretat, constituim, y posam»'(Constitucions y altres drets de Catalunya, Barcelona, 1995, p. 493). Para una aproximación al proceso de configuración del sector artesanal en Barcelona entre los siglos XII y XIII, véase Stephen P. BENSCH, Barcelona $i$ els seus dirigents, 1096-1291, Barcelona, 2000, especialmente las pp. 166-176.

${ }^{31}$ En el caso de la çiudad de Valencia, un privilegio de Pedro II, en 1283, concedía presencia en el Consell municipal a 15 oficios: «drapers, notaris, homes de mar, brunaters, freners, sabaters, sastres, pellicers, carnicers, corregers, fusters, pellers, ferrers, pescadors y barbers». Lista que, según Paulino Iradiel, respondía a «un ordẹn jerárquico no carente de signifiçado, pẹro basado quizas más en motivos cuantitativos y ocupacionales que en una consideración ideológica del prestigio y del honor» (P. IRADIEL, Corporaciones de oficio, p. 265).
} 
muestran un asentamiento representativo más acentuado por parte de determinados oficios.

En 1301, primera fecha para la cual disponemos de este tipo de información, sastres y freneros, junto a peleteros y plateros, son las profesiones que más componentes aportan al Consell - cuatro-, frente a los tres que proporcionan los carniceros, o los dos que representan, por ejemplo, a los curtidores o a los zapateros ${ }^{32}$.

En 1316, son estos últimos quienes ostentan el mayor número de representantes dentro del estamento artesanal - cinco-, mientras que los sastres mantienen sus cuatro miembros, y oficios como los de los freneros, herreros o plateros aportan únicamente dos ${ }^{33}$.

En 1350, sastres y zapateros vuelven a ocupar el primer lugar en cuanto a miembros elegidos para formar parte del Consell - cuatro-, seguidos de cerca por freneros, plateros y herreros con tres representantes. Pelaires, carpinteros, curtidores, peleteros, ropavejeros y manteros completan, en esta ocasión, la aportación artesanal con dos miembros por cada oficio ${ }^{34}$.

En 1390, la máxima contribución pertenece a los sastres, con cinco representantes, mientras que pelaires, freneros y tejedores cuentan con cuatro miembros por oficio, y carpinteros, ropavejeros, espaderos y panaderos acuden con tres. El resto de la representación de oficios incluye, entre otros, a zapateros, plateros, curtidores, tintoreros o manteros, que suministran dos representantes al Consell ${ }^{35}$.

En 1434, los sastres, de nuevo, acompañados de freneros, zapateros y carpinteros, ostentan el privilegio de contar con un mayor número de miembros - cuatro- en el Consell. Por su parte, los ropavejeros obtienen tres representantes, mientras que un nutrido grupo de ocupaciones artesanales, entre las cuales se hallan los plateros, herreros, pelaires, peleteros, tejedores de lana, tejedores de lino, curtidores, espaderos y ballesteros, queda limitado a dos presencias por oficio ${ }^{36}$.

Finalmente, en 1453 -en este acelerado repaso cronológico, que no pretende, en absoluto, ser exhaustivo, sino simplemente ilustrativo de una cierta tendencia mantenida a lo largo del tiempo en relación a la representación de los distintos oficios en el Consell de Cent barcelonés-, sastres, freneros y zapateros repiten escalafón con cuatro miembros, seguidos por los ropavejeros con tres. A continuación, plateros, herreros, pelaires, carpinteros, tejedores, curtidores y peleteros, entre otros, suministran dos representantes, quedando determinados oficios, como los marineros, barqueros, hortelanos, revendedores o taberneros, obligados a contentarse con un única aportación ${ }^{37}$.

\footnotetext{
${ }^{32} \mathrm{AHCB}, \mathrm{CC}$, Llibre del Consell, 1B I-1, f. 2r-v.

${ }^{33}$ Ibídem, I-4, ff. $2 \mathrm{v}-3 \mathrm{r}$.

${ }^{34}$ Ibídem, I-18, f. 4r-v.

${ }^{35}$ Ibídem, I-25, ff. $12 \mathrm{v}-14 \mathrm{r}$.

${ }^{36} \mathrm{AHCB}, \mathrm{CC}$, Deliberacions, 1B II-1, ff. 73v-74v.

${ }^{37}$ Ibídem, II-8, ff. 154r-155r.
} 
La constatación inmediata que se obtiene del análisis comparado de las relaciones que acabamos de exponer es la existencia de una jerarquización en la presencia institucional del estamento artesanal. Una jerarquización que, además, parece mantenerse estable a lo largo del tiempo, aparentemente inmutable ante el proceso de diversificación laboral que irá incrementando progresivamente el número de oficios con representación en el Consell de Cent $^{38}$, y que, en cualquier caso, tiende a solidificarse en la misma medida que la propia distribución estamental del Consell va adquiriendo una más clara definición política ${ }^{39}$. Así, sastres, freneros, zapateros, herreros y, en menor medida, plateros ${ }^{40}$, pelaires, carpinteros, tejedores, peleteros y ropavejeros tienden a diferenciarse del resto de oficios, ya sea por la constancia y continuidad de su participación política, ya sea por la importancia numérica con que ésta se materializa. No disponemos, sin embargo, de los elementos de juicio que podrían permitirnos entrar a valorar con la necesaria precisión las causas de dicha jerarquización, aunque, probablemente, ésta haya de estar relacionada con aspectos que tienen que ver con la antigüedad del oficio, el número de sus integrantes y la capacidad económica de éstos, la dignidad social de la profesión, o la importancia de dicha actividad en el proceso productivo y en el mercado urbano ${ }^{41}$.

En 1455 - dos años después de la última relación de oficios presentes en el gobierno de la ciudad que hemos tenido ocasión de comentar- Alfonso el Magnánimo, mediante privilegio real, establecía una nueva estructura compositiva para el Consell de Cent. En realidad, únicamente venía a confirmar los cambios que, de la mano de la Busca - el sindicato popular integrado básicamente por mercaderes, artistas y artesanos-, se habían producido en el gobierno municipal desde $1453^{42}$. Las modificaciones, que afectaban tanto la proporción representativa dentro del Consell - a partir de

\footnotetext{
${ }^{38}$ Compárense los 23 oficios mencionados en el privilegio real de 1257 con los 46 que pueden contabilizarse en la composición del Consell de Cent en 1453.

${ }^{39} \mathrm{~A}$ las vacilaciones observadas por Carme Batlle en relación a la división estamental de los primeros Consells, puesto que es posible detectar la presencia de artesanos en el grupo destinado al patriciado urbano (Carme BATLLE, La vida y las actividades de los mercaderes de Barcelona dedicados al comercio marítimo (siglo XIII), en Rosalba RAGOSTA (ed.), Le genti del mare Mediterraneo, Nápoles, 1981, pp. 300-301), hay que oponer la sugerente visión que, acerca de este mismo asunto, propone Charles-Emmanuel Dufourq, al mostrar hasta qué punto el grupo de los ciudadanos honrados en el Consell, por lo menos durante el siglo XIV, no correspondía a la estructura cerrada característica del siglo XV, sino que podía aparecer integrado por personajes notables de la ciudad, independientemente de su adscripción profesional, valorados por su experiencia en asuntos relacionados con el gobierno y la administración de la ciudad, y entre los cuales, obviamente, se encontraban miembros del sector artesanal de Barcelona (CharlesEmmanuel DUFOURCQ, «Honrats», «mercaders» et autres dans le Conseil des Cent au XIVè siècle, en Emilio SÁEZ; Cristina SÉGURA; Margarita CANTERA (coords.) La ciudad hispánica durante los siglos XIII al XVI, 3 vols., Madrid, 1985, vol. II, pp. 1361-1395).

${ }^{40} \mathrm{Para}$ la presencia de este oficio en el Consell de Cent a lo largo del siglo XIV, véase A. CUBELES, Els argenters I el Consell de Cent.

${ }^{41}$ Paulino Iradiel considera que dichos criterios influían tanto en la jerarquización del sector artesanal como en el acceso a representación política por parte de los oficios (P. IRADIEL, prestigio de las profesiones artesanales en Italia en A. I. PINI, Le arti in processione, p. 262.

${ }^{42}$ Para todo lo relacionado con la lucha por el poder municipal en la Barcelona de mediados del siglo XV, véase C. BATLLE, La crisis social y económica.
} 
ahora, 32 miembros por estamento- como el número y adscripción social de los consellers elegidos anualmente - cargo que pasaba a quedar repartido a nivel estamental, esto es, dos ciudadanos honrados, un mercader, un artista y un artesano--, significaban, entre otras cosas, la cristalización política del importante proceso de crecimiento socioeconómico del sector artesanal en Barcelona. Un proceso al cual no era ajena la cada vez más presente capacidad asociativa y organizativa de los oficios de la ciudad.

El texto del mencionado privilegio real resulta verdaderamente interesante por lo que se refiere a este último aspecto:

\begin{abstract}
...lo nombre dels quals menestrals sia compartit en aquesta forma, ço és que tots anys hagen a ésser e entrevenir en lo dit consell dos tansolament de cascuna de les confraries pus prop següents, ço és dels freners, sastres, perayres, çabaters, argenters e ferrers, e hu tansolament de cascuna de les confraries pus prop següents, ço és dels fusters caixers, pellers, texidors de draps de lana, texidors de drap de li, blanquers e assahonadors, e més hagen a ésser e entrevenir en lo dit consell hu tansolament de les confraries o officis següents, ço és de corredors de coll, ortolans, lauradors, mestres de cases e molers, mariners, matalafers, cotoners, flaçaders e senyalers, fustanyers, candelers de seu, bayners, gerrers, rajolers, mercers e bossers, pellicers, spasers e lancers, ballesters e viratoners, fusters bosquers, tintorers de draps de lana, boters de fusta grossa e prima e sparters, ço és aquelles dites confraries e officis les quals los dits consellers tots concordants volran, discorrent e variant-les cascun any e metent-les per orde fins de totes les prop dites confraries e officis de la dita ciutat sien entrevenguts en lo dit consell appellat de cent jurats. E més emperò, que, com en una confraria haurà diversos officis, aquells officis sien compresos en la dita confraria... ${ }^{43}$.
\end{abstract}

De entrada, quizá lo más llamativo de esta nueva lista de oficios sea la ratificación por ley de una jerarquía que, como hemos comprobado, ya parecía existir en la práctica: freneros, sastres, pelaires, zapateros, plateros y herreros adquirían una perpetua distinción - dos representantes permanentes en el Consell - respecto al resto de profesiones artesanales - limitadas a un único miembro y con una presencia no siempre garantizada en el Consellque ya no perderían a lo largo del siglo XV.

Pero no es exactamente eso lo que más nos interesa destacar ahora de dicha relación, sino el importante matiz que se introduce en el momento de designar la representación artesanal en el gobierno de la ciudad. El texto habla de "confraries" para referirse a aquellos oficios que ocupan el lugar más alto en la jerarquía artesanal, y lo mismo sucede en relación al segundo bloque de profesiones que viene a continuación de esta supuesta "élite". Para el resto, sin embargo, se utiliza una terminología más ambigua, "confraries o officis", que, parece claro, tiene que ver con la disposición por la cual el propio documento determina que todos aquellos oficios que compartan una misma cofradía han de ser representados institucionalmente por ésta.

\footnotetext{
${ }^{43}$ Reproducimos aquí la transcripción que, de dicho documento, puede encontrarse en M. TinTó, Els gremis a la Barcelona medieval, pp. 14-16.
} 
A estas alturas del siglo XV, tal como apunta Bonnassie, la cofradía parecía haber asumido la capacidad representativa del oficio, superando aquellos aspectos asistenciales, religiosos o administrativos que la caracterizaban en un inicio ${ }^{44}$. Aportaba, además, una entidad de tipo jurídico -el privilegio real que permitía su creación- al reconocimiento institucional que ya poseía el oficio, en lo que era una nueva manifestación de la necesidad, por parte del sector artesanal, de adecuar su realidad socioeconómica a su capacidad de intervención política ${ }^{45}$. En este contexto, y esa es una de las posibles lecturas que puede hacerse del privilegio de 1455, "cofradía", "prestigio" e, incluso, "poder" son conceptos que aparecen relacionados.

Retomemos por un instante el documento con el que iniciábamos este artículo, y en el cual el oficio de los calceteros de Barcelona reclamaba su derecho a tener representación política en el Consell de Cent. La creación de una cofradía propia -en 1455, bajo la advocación de San Sebastián ${ }^{46}$ - había materializado la independización de dicho oficio respecto del de los sastres - en cuya cofradía probablemente habían estado integrados hasta la fecha-, en una iniciativa posibilitada, entre otros factores, por el incremento en el número de artesanos dedicados a dicha profesión ${ }^{47}$. Esta nueva situación, en la práctica, no se había visto beneficiada, hasta la fecha, por el privilegio que aquel mismo año había concedido Alfonso el Magnánimo a la ciudad, de tal manera que, a pesar de estar definido, tanto institucional como jurídicamente, y de poseer una imagen propia, simbolizada en el pendón emblemático bajo el cual sus componentes desfilaban en los actos públicos, el oficio de los calceteros permanecía marginado del poder político ${ }^{48}$. Su protesta, en cuanto que aduce la existencia de un agravio comparativo, sirve perfectamente para establecer una clara relación, dentro del mundo artesanal de la Barcelona bajomedieval, entre crecimiento social, forma organizativa y presencia

${ }^{44} \mathrm{P}$. BONNASSIE, La organización del trabajo, p. 34.

${ }^{45}$ P. IRADIEL, Corporaciones de oficio, p. 261.

${ }^{46}$ AHCB, Fons gremial, 2B. 49-1, ff. 5r-6y. El privilegio real, concedido por Juan, rey de Navarra y lugarteniente generai de Alfonso el Ṃagnanimo en Cataluña, ademáș de los aspectos relacionados con la organización y funcionamiento de dicha cofradía (elecciones de cargos dirigentes gestión economica, etc.), o con los elementos devocionales y asistenciales propios de este tipo de asociaciones (ayuda y atención a los miembros necesitados, veneración del patrón bajo cuya protección se situabá la cofradía, etc.), incluía igualmente capítulos dedicados exclusivamente a la reglamentación y regulación laboral de dicho oficio.

${ }^{47}$ «E sia veritat que, aprés la concessió del privilegi novell de elecció de consellers e Consell de la dita ciutat, sia stat creat en la dita ciutat lo dit offici dels calçaters, separat e distinct de l'officici dels sastres, ab concessió de confraria del gloriós màrtir Sent Sebastià, patró lur, en la sglésia de Sent Johan de la dita ciutat, axí que vuy són XXXX casats en la dita ciutat, entre los quals ha molts hòmens qui basten a consellar la dita ciutat, axí bé com los altres officis e confraries» (AHCB, Fons gremial, 2A.2-4).

${ }^{48}$ En el conflicto que, a lo largo de toda la segunda mitad del siglo XV, enfrentó a calceteros y sastres en Barcelona acerca de la facultad de estos últimos para ejercer también el oficio de los primeros, y en el cual intervino siempre como mediador el municipio -tal como solía ser habitual en este tipo de incidentes-, podría, tal vez, encontrarse el trasfondo de dicha circunstancia. Véase, para este tema, P. BoNNASSIE, La organización del trabajo, p. 61. 
política ${ }^{49}$. Relación que, sin embargo, en el caso de los calceteros, como hecho - no sabemos hasta qué punto- excepcional, no parece darse de forma automática.

La no correlación directa entre privilegio real y participación municipal que experimentan los calceteros barceloneses ha de servirnos, finalmente, para situar al estamento artesanal dentro del juego de fuerzas en el que se inscribe su propio crecimiento sociopolítico. Robert Freitag, en su estudio sobre los tintoreros de la ciudad de Perpiñán, considera que en la búsqueda, por parte de los oficios, de un privilegio que legitime a perpetuidad su capacidad asociativa, se ha de interpretar el deseo de éstos de obtener una autonomía respecto del control municipal; e, igualmente, en la concesión del monarca, un no confesado intento de debilitar a las clases dirigentes urbanas ${ }^{50}$. Por su parte, son diversos los trabajos sobre el artesanado medieval que han mostrado el grado de intervencionismo que podían llegar a ejercer las autoridades municipales a la hora de controlar las aspiraciones estatutarias de los oficios ${ }^{51}$. Entre ambos factores, entre la fuerza legitimadora del soberano y la facultad normativa del municipio, se mueven no únicamente lo calceteros -quienes, como ya hemos visto, lo que reclaman es la aplicación, por parte de los regidores consistoriales, de un privilegio real que les afecta directamente-, sino el conjunto entero de corporaciones artesanales. Se trata, en definitiva, de una compleja red de relaciones que mezcla - pero también enfrenta- los intereses particulares de cada oficio con los más generales de la universitas $^{52}$; los del estamento menestral con los de las élites de la ciudad;

${ }^{49} \mathrm{El}$ motivo esgrimido por los tintoreros de Valencia para solicitar a Juan I, en 1393, el privilegio fundacional de una cofradía de oficio, incidía en este mismo orden de cosas: «...que com senyor en temps passat lo dit offici de Tintorers sie estat en poca reputacio e los homens usants de aquell eran fort pochs e per co aquells james no han feta entre si confraria alguna ni usants de aquell eran fort pochs e per co aquells james no han feta entre si confraria alguna ni
almoyna. E ara per Dei gratiam aquell dit offici es molt creegut e es en gran reputacio e los
homens usants de aquell son molts e en gran nombre per la qual raho aquells volrien e desijen fer entre si confraria o almoyna segons altres officis de la dita clutat han acustumat e acostumen fer» (F. de BOFARULL, Gremios y cofradías, CODOIN, vol. XLI, p. 31).

${ }^{50}$ Robert FREITAG, La protección real de los gremios en el siglo XIV y los tintoreros de Perpiñán, en VIII Congreso de Historia de la Corona de Aragón, 6 vols., Valencia, 1970, vol II, pp. 141-162.

${ }^{51}$ Véase M. RIU, Aportación a la organización gremial, pp. 554-555, en relación a la protesta municipal ante el privilegio real obtenido por los tejedores de lana de Barcelona en 1387; o J.-F. CABESTANY, Els mestres sabaters, p. 77, para la problemática surgida en torno a la creación de la cofradía de los costureros barceloneses en 1397. Véase, igualmente, María Isabel FALCÓN, La fundación de una cofradía gremial: la de los bajadores de paños de Zaragoza, "Anuario de Estudios Medievales, 18 (1988), p. 563, donde se describe como el privilegio real otorgado, en 1454, a los bajadores zaragozanos hubo de pasar por las manos de los jurados de la ciudad, $y$ 1454, a los bajadores zaragozanos hubo de pasar por las manos de los jurados de la ciudad, y
recibir su aprobación, antes de poder entrar en vigor. Para una circunstancia similar, en la isla

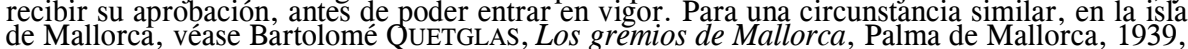
pp. 7-9.

${ }^{52}$ Antonio Collantes cuestiona, en cierta forma, la autonomía de las cofradías de oficio, al apuntar que las ordenanzas municipales que, junto a los capítulos contenidos en los privilegios reales, regulaban su funcionamiento, en realidad «no reflejan tanto o necesariamente los intereses "gremialistas" de los menestrales, cuanto los del poder público, como garante del orden social..." (Antonio COLLANTES, Los poderes públicos y las ordenanzas de oficios, en María BARCELÓ(ed.)", encontrarse un ejemplo de dicha argumentación en la postura adoptada por los consellers de Barcelona, en 1454, cuando desestimaron otorgar determinadas ordenanzas municipales que les habían sido solicitadas tanto por los sastres como por los maestros de obras de la ciudad, al considerar que su posible aprobación implicaría «gran dan a la cosa pública de la dita ciutat» (AHCB, CC, Deliberacions, 1B II-8, f. 198r). 
o los de la propia ciudad con los de la monarquía; y a la cual no es, en absoluto, ajena la cofradía ${ }^{53}$.

\section{LA PARTICIPACIÓN DEL ESTAMENTO ARTESANAL EN LAS CEREMONIAS DE ENTRADA REAL}

Ni siquiera lo anteriormente expuesto en relación a las carencias que el estudio del artesanado en la Barcelona bajomedieval presenta en la actualidad es aplicable al tema de la entrada real. No existe, a este respecto, ninguna tradición historiográfica, y son escasos los trabajos que han llamado la atención sobre este tipo de ceremonia, no únicamente en la ciudad de Barcelona, sino en el conjunto de la Cataluña medieval ${ }^{54}$.

En cualquier caso, los problemas son, en cierta manera, los mismos. No sabemos gran cosa acerca de la gestación medieval y posterior evolución de esta celebración hasta, por lo menos, el siglo XIV ${ }^{55}$, y la realidad es que tampoco parece existir una clara unanimidad a la hora de encontrar una definición pertinente para dicho evento ${ }^{56}$. En otras palabras, conocemos el sentido básico que una entrada real tiene en la Barcelona de inicios del siglo

\footnotetext{
${ }^{53}$ No olvidemos que se trata de una asociación que combina elementos religiosos, sociales, políticos y económicos, y que puede estar integrada por un único oficio -en cuyo caso se establece una identificación profunda entre ambos-o agrupar a diversas profesiones, pero que, al mismo tiempo, es capaz de admitir la presencia de miembros a título personal, independientemente de su adscripción profesional o, por el contrario, mostrarse muy restrictiva respecto a este asunto, hasta el punto de -como sucedia en el caso de los calceteros barceloneses- condicionar el ejercicio del oficio a la pertenencia a la cofradía.

${ }^{54}$ Para la Barcelona bajomedieval, vẹ́anse Kenneth KREITNER, Music and Civic Ceremony in Late Fifteenth Century Barcelona (tesis doctoral inédita), Duke University, Durham, 1990; Miguel RAUFAST CHICO, ¿Negociar la entrada del rey? La entrada real de Juan II en Barcelona (1458), "Anuario de Estudios Medievales", 36/1 (2006), pp. 295-333; IDEM, ¿Un mismo ceremonial para dos dinastías? Las entradas reales de Martín el Humano (1397)' y'Fernando I (1412) en Barcelona "En la España Medieval", 30 (2007) (en vías de publicacion). Por lo que respecta a los estudios que abordan el tema en' la Edad Moderna, véanse, entre otros, Lenke KOVACS, La ciutat com a escenari: les entrades reials i la festa urbana, "Barcelona. Quaderns d'Historia", 9 (2003), pp. 71-81; Ma Angeles PEREZ SAMPER, El rey y la ciudad. La entrada rea de Carlos I en Barcelona, "Studia Historica", 6 (1988), pp. 439-448; EADEM, La presencia de rey ausente: las visitas reales a Cataluña en la época moderna, en Agustín GONZALEZ ENCISO Jesús $M^{\mathrm{a}}$ USUNÁRIZ GARAYOA (dirs.) Imagen del rey, imagen de los reinos. Las ceremonias públicas en la España Moderna (1500-1814), Pamplona, 1999, pp. 19-61. En cuanto a la situación en el resto de Cataluña, así como también en el conjunto de la Península Ibérica, puede encontrarse un breve resumen bibliográfico en M. RAUFAST, ¿Negociar la entrada del rey?, pp.
$2-3$, nota 2 .

${ }^{55}$ Una celebración que hunde sus raíces en el mundo clásico y que parece tomar prestada parte de su estructura y de su imaginería visual tanto del triumphus romano (recibimiento ofrecido al emperador o a un general victorioso a su llegada a Roma) como del adventus bíblico (entrada de emperador o a un general victorioso a su llegada a Roma) como del adventus bíblico (entrada de Jesus en Jerusalén). Véanse, para este tema, Ernst H. KANTOROWICZ, The "King's Advent" and the Enigmatic Panels in the Doors of Santa Sabina "Art Bulletin", 26:4 (1944), pp. 207-231; Michael MCCORMICK, Eternal victory. Triumphal Rulership in Late Antiquity, Byzantium, and the Early Medieval West, Cambridge, 1986; H. S. VERSNEL, Triumphus.
Origin, Development and Meaning of the Roman Triumph, Leiden, 1970.

${ }^{56} \mathrm{El}$ muestrario es amplio y verdaderamente diverso, con expresiones que van desde "triunfo político" o "ceremonia de purificación" hasta "momento de diálogo" o "contrato social" según se pretenda resaltar el papel jugado por la figura del rey o, por el contrario, se quiera hacer hincapié en la intervención activa del municipio en estas celebraciones. Destaca, por encima de todas ellas la utilizada por Elie Konigson al referirse a la entrada real medieval como un "hecho social total" (Elie KoNIGSON, L'espace théâtral médiéval, París, 1975, p. 254), en una clara referencia a su complejidad formal y simbólica.
} 
XV - esto es, celebrar exclusivamente la primera visita a la ciudad del monarca, de la reina o del primogénito al trono ${ }^{57}-$, pero ignoramos aún cuál es el proceso que lleva, por ejemplo, desde el 801, año en que disponemos de la primera noticia sobre una posible ceremonia de recepción real por parte de la ciudad ${ }^{58}$, hasta el 1397, fecha que nos proporciona la primera descripción explícita y detallada de una entrada real, y que es, a la vez, el primer indicio que poseemos de la participación de los oficios artesanales en estas ceremonias $^{59}$.

Para el siglo XV, sin embargo, gracias - como ya hemos avanzado en el inicio de este artículo ${ }^{60}$ - a la mayor riqueza documental del período, sí nos es posible esbozar con cierta exactitud tanto la estructura y elementos que componen el modelo de una entrada real en Barcelona, como el desarrollo escénico de la misma. A grandes rasgos, la ceremonia se iniciaba con un recibimiento institucional previo, en lo que era el encuentro, fuera de las murallas de la ciudad, entre el monarca y las autoridades y personalidades del municipio. Seguía - usualmente, al día siguiente- la entrada del soberano en el recinto urbano y el inmediato juramento, por parte de éste, de las libertades y privilegios del lugar. Tras dicho acto, se iniciaba el desfile de los oficios de la ciudad, quienes, pasando ante el monarca, le rendían honores con sus bailes y representaciones, para dirigirse, a continuación y a través de un itinerario definido de antemano, hacia la Catedral. El rey se incorporaba - siempre a caballo - a dicho desfile, ocupando el último lugar en la comitiva y, bajo palio, era conducido por los consellers y representantes de los diferentes estamentos barceloneses hasta las proximidades de la Seu. Allí, el soberano era acogido en procesión por el clero y, una vez juradas las libertades y privilegios de la Iglesia, penetraba en el templo. Tras las oraciones y rituales eclesiásticos pertinentes, la ceremonia de entrada real concluía con el monarca encaminándose, en compañía de los regidores consistoriales, hacia su alojamiento en la ciudad ${ }^{61}$. Toda una serie de actos paralelos o complementarios, desde la celebración de justas hasta los bailes y la iluminación efectista o el adorno de calles y casas, punteaban un complejo ritual capaz de integrar

\footnotetext{
${ }^{57}$ AHCB, CC, Llibre del Consell, 1B I-28, f. 9v. Se trata de la argumentación con la que los consellers de Barcelona responden a Martín el Humano, en 1400, ante las pretensiones del monarca de ser recibido solemnemente por segunda vez, tras la acogida que ya se le había tributado en 1397

${ }^{58}$ ASTRONOMUS, Vita Hludovici imperatoris (Monumenta Germaniae Historica. Scriptores Rerum Germanicarum, 64), Hannover, 1995, pp. 318-320. Se trata de la entrada de Luís el Piadoso en Barcelona, tras el sitio victorioso contra los árabes. Véase, para un análisis de esta ceremonia, M. MCCORMICK, Eternal victory, p. 375.

${ }^{59} \mathrm{El}$ Cronicó de Guillem Mascaró (BC, Ms. 485) incluye, entre sus páginas, una colorida y detallada descripción de la entrada real de Martín el Humano, en 1397, en Barcẹlona. Para todo lo referente a dicha entrada, remitimos, a partir de ahora, a M. RAUFAST, ¿Un mismo ceremonial para dos dinastías? Para una transcripción del fragmento del Cronicó corréspondiente a la entrada para dos dinastías? Para una transcripción del fragmento del Cronicó correspondiente a la entrada Somni (edición de Stefano CINGOLANI), Barcelona, 2006, pp. 275-276.

${ }^{60}$ Véanse notas 6 y 7.

${ }^{61}$ Aunque no utiliza únicamente referencias bajomedievales, sino también pertenecientes al siglo XVI, es útil la consulta, para una aproximaciôn a este esquema ceremonial, de L. KOVACS, La ciutat com a escenari.
} 
-en lo que algunos han considerado como el intento de reconstrucción de una imagen ideal de la estructura social urbana ${ }^{62}-$ a los diferentes estamentos de Barcelona y envolverlos en una dinámica cohesionadora que, además de servir para celebrar la figura del monarca, se revelaba enormemente válida para compensar los efectos diferenciadores que, en la práctica, fragmentaban la universitas $^{63}$.

Dentro de este conjunto ceremonial, que Lawrence Bryant percibe en términos de "bricolaje" barcelonés y en qué forma se articulaba su participación?

La respuesta a ambas cuestiones, lamentablemente, queda a expensas de lo que nos puedan decir las fuentes institucionales municipales de la época, puesto que la documentación gremial anterior al siglo XVI que se ha podido conservar en la ciudad de Barcelona resulta extremadamente discontinua y desigual, reducida en ocasiones a meros testimoniajes aislados del funcionamiento interno de las diferentes asociaciones artesanales (libros de reuniones, libros de cuentas, libros de privilegios y ordenanzas, etc.), y no ha sido capaz -hasta la fecha, por lo menos- de aportar información destacada sobre este tema. Así, los procesos particulares de cada oficio en relación a su participación en las ceremonias de entrada real bajomedievales nos son absolutamente desconocidos, y hemos de contentarnos con la visión, mucho menos detallada y sí más genérica, que emana de los registros oficiales municipales.

En 1467, ante la inminente llegada a Barcelona de Juan, duque de Calabria, primogénito del rey Renato de Anjou - el nuevo monarca en el Principado, tras la muerte de Pedro de Portugal-, los consellers de la ciudad enviaron a sus verguers - oficiales municipales encargados de llevar la verga, o símbolo representativo de la autoridad consistorial - a visitar a los altos cargos de cada oficio, a fin de reclamar su participación en la celebración de dicha entrada real ${ }^{65}$. Se trataba del protocolario y habitual gesto con el cual se activaba la preparación, no tan sólo del desfile artesanal, sino también de todos aquellos momentos de la ceremonia en los cuales dicho estamento desempeñaba algún protagonismo. Momentos que, al menos para la segunda mitad del siglo XV, sí nos es posible delimitar.

\footnotetext{
${ }^{62}$ Teresa Ferrer VALLS, La fiesta cívica en la ciudad de Valencia en el siglo XV, en Evangelina RODRÍGUEZ (ed.), Cultura y representación en la Edad Media, Valencia, 1994, p.

${ }^{63}$ Según G. BALANDIER, El poder en escenas, p. 41: «Si se admite que toda sociedad está siempre en transformación, nunca estancada, que su unidad no se realiza sino en la imagen que todo conformes con la realidad vivida , qu puede comprender entonces mejor la necesidad de producir efectos que asuman una función compensatoria».

${ }^{64}$ «...the urban spectacles brought together preexisting elements that amalgamated over time to form something distinct from the parts, or a bricolage» (Lawrence M. BRYANT, Configurations of the Community in Late Medieval Spectacles: Paris and London During the Dual Monarchy, en B. A. HANAWALT, City and Spectacle, p. 5).

${ }^{65}$ «...los honorables consellers tramateran los verguers llurs per los caps dels officis de la present ciutat, pregant e exortants aquells fossen prests e apparallassen les coses e entremesos que havian a ffer la jornada de la festa fahedora per la intrada del dit senyor» (Llibre de les Solemnitats, vol. 1, p. 286).
} 
El recibimiento al monarca en las inmediaciones de la ciudad contaba ya, en calidad de primer acto institucional, con la presencia de elementos destacados del sector artesanal ${ }^{66}$. En ocasiones, dichos encuentros -que normalmente tenían lugar muy avanzado el día- eran ambientados escénicamente por la luz de numerosas antorchas de cera, cuyo transporte y responsabilidad quedaba en manos de los joves (oficiales) de los oficios ${ }^{67}$. Y en circunstancias muy particulares - tal como aconteció en la ya señalada entrada del duque de Calabria en 1467, celebrada en plena Guerra Civil catalana (1462-1472) - , la aportación de dicho estamento adquiría un rango fundamental, al quedar emparentado el papel de los oficios barceloneses en las entradas reales con la contribución de éstos a la hueste urbana de la ciudad ${ }^{68}$, en la medida en que se combinaba la ceremonia de recepción con la protección armada del ilustre visitante ${ }^{69}$.

Ya en plena ceremonia, el desfile de los oficios, previamente ordenado en su disposición escénica ${ }^{70}$, ponía en marcha, por parte de las diferentes agrupaciones artesanales, toda una serie de recursos expresivos comunes (entremeses y representaciones en los que se combinaban las

${ }^{66}$ Tal como sucedió, por ejemplo, con motivo de la entrada real de Fernando II en Barcelona, en 1479: «E ans de la entrada del dit senyor, los honorables consellers, seguint lo bon costum e prática anticada de la dita Ciutat, en companyhia del governador de Cathalunya e del vaguer, palla, cónsols de la Lotge, e de alguns promens de tots staments, per fer reverència e besar la ma al dit senyor, ajustats en la Casa de la Ciutat, partiran de la dita Casa a cavall, axint fora la Ciutat fins a la albareda qui es passada la riera de Sants, e allí speraren lo dit senyor...» (Ibídem, pp.320321)

${ }^{67} \mathrm{El} \mathrm{recibimiento} \mathrm{otorgado} \mathrm{a} \mathrm{la} \mathrm{reina} \mathrm{Isabel,} \mathrm{en} \mathrm{1481,} \mathrm{resulta} \mathrm{paradigmático} \mathrm{acerca} \mathrm{de} \mathrm{este}$ aspecto: «E com ja fos hora tarda e quasi foscant, los honorables consellers, segons ja era aspecto: "E com ja fos hora tarda e quasi foscant, los honorables consellers, segons ja era delliberat, faheran venir LXXV. antorxes de cera, de aquelles CL. que havien fetes aparellar per causa de la dita venguda, e enceses les dites antorxes, les quals [portaven] jovent de confraries, emprades per los dits honorables consellers, exints de la dita ciutat, vingueran fins a la dita albereda hon trobaren la dita senyora...» (Ibidem, p. 336). Igualmente, en el Llibre del Clavar de la cofradía de los freneros de Barcelona correspondiente a 1459 consta el pago a «X òmens qu portaren X antorxes con lo rey e la reyna entràs, en una posible referencia a la entrada real de Juan II celebrada en noviembre de 1458 (AHCB,' Fons gremial, 2B. 36-7, f. 12v).

${ }^{68}$ Para el tema de la hueste de Barcelona en la Edad Media, véanse A. DuRAN, Barcelona la seva historia, vol. II, pp. 109-112; Santiago SOBREQUÉS I VIDAL; Jaume SOBRRQUES I M.T. FERRER I MALLOL. El sagramental: una milícia camperola dirigida per Barcelona, "Barcelona. Quaderns d'Història", 1 (1r semestre de 1995), pp. 61-70.

${ }^{69}$ «...per ço que lo dit senyor vingués segurament e acompenyat, delliberaren amprạr totes les confraries de la present ciutat, ço es, cascuna particularment t...] $\mathrm{E}$ les dites cofraries, ço es, cascuna d'elles oferí als dits honorables consellers hun gran nombre de gent armada, çui la cascuna delles, oferi als dits jornada de la dita entrada foren prests e aperellats de axir fora la dita ciutat, per rebre lo dit senyor primogenit, acompanyant aquell emsemps ab los dits honorables consellers dins la present ciutat» (Llibre de les Solemnitats, vol. I, p. 287). Una situación similar se había vivido ya en 1461, con motivo de la entrada en Barcelona del príncipe de Viana, acabado el confinamiento en Morella al que su padre, Juan II, le había reducido: «...e tota la Rambla fonch plena a dos cos daca e della de gent ben armada e ben en orda, quascuns ab lurs stendarts, que s creu hi havia passats IIII mil. homens armats, manestrals de diverses confraries...» (Dietari de la Deputació, CODOIN, XLIX, p. 30).

${ }^{70}$ Un proceso en el cual, hemos de deducir, intervenían tanto las autoridades municipales como los representantes de los propios oficios. A pesar de que no contamos con informacion explícita los representantes de los propios oficios a pesar de que no contamos cón informacion explícita Sobre ello en la ciudad de Barcelona, si disponemos de algunos casos válidos para la Valencia de jurats de la misma, tras intercambiar opiniones con los representantes de cada oficio, acordaron con éstos «sobre lurs colors e liurees e sobre lorde de lur exir o anar e tornar" (Salvador CARRERES ZACARÉS, Ensayo de una bibliografía de libros de fiestas celebradas en Valencia y su antiguo reino, Valencia, 1925, p. 61 del apéndice documental). 
evocaciones bíblicas con el imaginario medieval, bailes y danzas, emblemas y vestimentas) que, al mismo tiempo, eran utilizados para señalar, dentro de la aparente homogeneidad estamental, la identidad particular y distintiva de cada oficio ${ }^{71}$. El organizado desfile corporativo de los artesanos barceloneses servía, igualmente, para hacer visible la estructuración jerárquica en el interior de los oficios: tras el correspondiente pendón identificativo - que era inclinado, en señal de reverencia, a su paso ante el monarca ${ }^{72}-$, se diferenciaba la presencia de los oficiales - joves o macips, en la terminología de la época-, encargados de la ejecución de los diferentes bailes con los que se amenizaba el trayecto de la comitiva, de la de los maestros, mucho más contenidos en sus gestos y portadores de ropajes o elementos intencionadamente distintivos ${ }^{73}$.

Y mientras los oficios, tras hacer honor al soberano, iniciaban un colorista recorrido que, a través de las calles atestadas de la ciudad, había de llevarles hasta las proximidades de la Catedral, éste, abandonando el catafalco desde el cual había contemplado el espectáculo, se incorporaba a la comitiva y la concluía jerárquicamente con su presencia, custodiado bajo palio a lo largo del trayecto, y rodeado, en todo momento, por las autoridades municipales. El sector artesanal volvía a significarse en este fase, por cuanto la tarea -marcadamente simbólica - de guiar la montura en la que cabalgaba el monarca quedaba repartida entre personalidades escogidas de los diferentes estamentos de la ciudad ${ }^{74}$.

\footnotetext{
${ }^{71}$ Un complejo juego de relaciones que iba más allá del interior del estamento artesanal, por cuanto era práctica habitual, por parte de los consistorios municipales, colaborar en los gastos de las cofradías con motivo de fiestas y celebraciones, además de prestar algunos de los entremeses propios de la ciudad -como es el caso del águila, en Barcelona- para el desfile de los oficios en propios entradas reales. Así, en 1430, Barcelona costeó la reparación del «entremès de l'offici dels peyers, que cascun any fan en la festa del preciós cors de Jhesuchrist, del martiri de Sant Sabestià» (AHCB, CC, Clavaria, 1B XI-45, f. 105r). En Tarragona, la ciudad asumió el gasto ocasionado por la contratación de los juglares utilizados para acompañar los bailes de las cofradías de los pescadores, zapateros, pellejeros y hortelanos en la entrada de la reina en 1383 (Actes municipals. Col leccio de Documents de l'Arxiu Històric Municipal de Tarragona, 10 vols. Tarragona, 1982-1995, vol. 4, pp. 93-94). Acerca de este mismo aspecto en la ciudad de Valencia, véase T. FERRER, La fiesta civica, p. 151.

${ }^{72}$ Așí consta en la relación de la entrada de Fernando I en 1479: «E passades totes les dites confraries, e feta per cascuna reverencia al dit senyor, abaxant cascuna son panó fins en terra...» Llibre de les Solemnitats, vol. I, p. 325)

${ }^{73}$ Aunque las relaciones conservadas de entradas reales en Barcelona no son excesivamente expresivas acerca de todos estos detalles, sí es posible, esporádicamente, encontrar referencias determinantes. Así, en la celebración de la entrada de Pedro de Portugal, en 1464, se nos describe tanto la participacion de los oficiales merceros: "lurs macips vestits de camises blanques de lil, (Dietari o Llibre de Jornades, p. 188), como la de los maestros sastres: «vengueren los sartres (Dietari o Llibre de Jornades, p. 188), como la de los maestros sastres: "vengueren los sartres
armats e lurs prohomens al detraç, portants spervers en les mans, segons que n'an antich privilegi» (Ibidem, p. 189). La doçumentación correspondiente a la ciudad de Valencia ofrece, igualmente, un ejemplo muy preciso -con motivo de la entrada de los duques de Gerona, en 1373- sobre esta jerarquización escénica dentro de cada oficio: «una de les coses que mils ornaven cascun Offici eren los promens, ab çurambres de cendat o de tafata, qui anaven apres de lurs balladors» (S. CARRERES, Ensayo de una bibliografía, p. 34 del apéndice documental).

${ }^{74}$ Podemos encontrar un claro ejemplo de ello en la entrada, en 1458, de Juan II en Barcelona: «E tiraren-lo per dos cordons de seda groga e vermella de quascuna part IIII manestrals, IIII artistes, IIII mercaders e IIII ciutadans honrats» (Dietari o Llibre de Jornades, p. 106). Para la entrada del príncipe de. Viana, en 1460 , conocemos incluso la identidad de los artesanos designados para tal misiọn: «Ffrancesch Gallard, vadrier, Anthoni Bells, argenter, Anthoni Seguer, perayre, Pere Juliol, cuyrasser, per los manestrals» (Ibídem, p. 121).
} 
Asimismo, no hemos de olvidar la presencia - desde 1453, cuando el artesanado consigue representación entre los cargos máximos del poder municipal en Barcelona- del quinto conseller, o conseller artesano, entre los portadores de las varas del palio bajo el cual el rey atraviesa la ciudad ${ }^{75}$. Su participación en el conjunto de la ceremonia, junto al resto de los regidores municipales, se extendía, como ya hemos visto anteriormente, desde el inicial recibimiento previo a la entrada hasta el acompañamiento final al monarca hasta su alojamiento, en lo que era un ritual permanente de gestos calculados, precedencias rigurosas y escenificaciones jerarquizadas en el cual se materializaba tanto la relación institucional entre municipio y monarquía como las dinámicas internas, sociales y políticas, de la ciudad.

La figura del quinto conseller nos sirve, en cualquier caso, para simbolizar el alcance de la participación artesanal en las ceremonias de entrada real en la Barcelona del siglo XV. Participación que no se reduce a su expresión más exclusiva - esto es, el desfile de los oficios- sino que se manifiesta, en diferente grado y sentido, a lo largo del conjunto de la celebración. Acciones y presencias diversas cuya articulación e inserción dentro del evento parecen responsabilidad tanto de las autoridades municipales como de los propios oficios ${ }^{76}$, en una confluencia de intereses particulares y generales que lleva, a unos y a otros, a aceptar participar en la construcción -ideal y, por lo tanto, en cierta medida ficticia- de esa imagen ordenada ${ }^{77}$,

\footnotetext{
${ }^{75}$ Es el caso, por ejemplo, del frenero Joan Sunyer, quien, en calidad de «conseller quint», fue el encargado de sujetar la vara delantera de la parte izquierda del palio en la entrada del duque des Calabria en 146\%. Para un detallado estudio sobre la minuciosa y jerarquizada colocacion de los portadores del palio en diferentes tipos de celebraciones, vease Ramon MIRO I BALDRICH, civils i religioses en els segles XV-mitjan XVII, "Palestra Universitaria", 8 (1996), pp. 63-80.

${ }^{76}$ Es posible encontrar privilegios reales concedidos a cofradías de oficio en los que aparece contemplada la participación de éstas en las ceremonias de entrada real. Es el caso de los tintoreros de Valencia, a quienes Juan I permite, en 1393, realizar tallas entre los miembros de la cofradía para poder atender, entre otras cosas, a «les despenses ques fan per fer honor a vo senyor en la entrada» (F. de BoFARULL, Gremios y cofradías, CODOIN, vol. XLI, p. 38). O el de los zapateros de la misma ciudad, quienes, en 1421 , obtienen de la reina Maria esposa y lugarteniente general de Alfonso el Magnánimo la facultad de poder reunirse entre ellos siempre que dicho oficio «per entrada del Rey o reyna de primogenit po nativitat de aquell o per neempre que dicho oficio «per entrada del Rey o reyna, de primogenit o nativitat de aquell o per negocis de la dita Ciutat, haurá fer aparell e alegries o altres qualsevol coses» (Leopoldo PILES, Estudio sobre el gremio de zapateros, Valencia, 1959, p. 126). En Barcelona, el privilegio real de Martín el Humano, en 1408, a los barbers e cirurgians -recordemos, oficios no artesanales, pertenecientes al estamento de los artistas- también incidía en la facultad de la cofradía para establecer imposiciones económicas entre sus componentes, «en cas que per lo senyor Rey o per sos oficials sera manat al dit offici de fer alscunes messions o despeses axi com per entrada de Rey per novella Regina o per primogenit o per qualque altres rahons que lo dit senyor Rey sos official o la ciutat ordonara" (F. de BOFARULL, Gremios y cofradías, CODOIN, vol. XLI, p. 283).

${ }^{77}$ Cuya más prosaica evidencia es, precisamente, la existencia de los así llamados "ordenadores", personas designadas para controlar el complejo protocolo de precedencias que inundaba cualquier celebracion cívica urbana y encargadas de asegurar el correcto desarrollo del ciudad. Así, en 1461, «Gaspar de Raiadell, ciutadà; Barthomeu Fferrer, mercader: obrers. Johan Garau, notari; Ffrancesch Rigau, texidor de li» desempeñaron el cargo de "ordonadors" en la

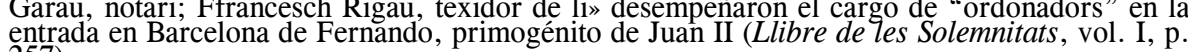
257)
} 
armoniosamente estructurada y jerarquizada de la sociedad medieval urbana que intenta transmitir la puesta en escena de una entrada real ${ }^{78}$.

\section{LA VISUALIZACIÓN DE UNA JERARQUÍA: EL DESFILE DE LOS OFICIOS}

\subsection{Historia, fuentes y terminología}

Al igual que nos sucedía cuando hablábamos de la consolidación medieval de la ceremonia de entrada real, nos es igualmente difícil - por no decir, simplemente, imposible - precisar cómo ni cuándo el desfile del estamento artesanal hizo su aparición en este tipo de evento. Como ya hemos comentado, la primera mención explícita que poseemos acerca de la participación escénica de los oficios barceloneses en una entrada real pertenece a 1397, con motivo de la llegada a la ciudad de Martín el Humano. Las noticias anteriores a esa fecha nos informan, sin grandes detalles, del recibimiento otorgado por el municipio tanto a reyes como a reinas, pero en ningún momento se hacen eco de un posible desfile a cargo del estamento $\operatorname{artesanal}^{79}$. Este hecho, por otra parte, parece coincidir con lo que acontece en Valencia, donde la aparición de los oficios en desfile únicamente parece estar documentada desde $1373^{80}$. Los esfuerzos que, en ese preciso año, llevaron a cabo tanto los regidores municipales como los representantes artesanales valencianos para coordinar la participación de los oficios en la entrada de los duques de Gerona, han sido interpretados por Paulino Iradiel como el punto de partida del desfile artesanal - tal como lo conocemos durante el siglo $\mathrm{XV}$ - en dicha ciudad ${ }^{81}$.

Obviamente, hemos de sospechar que los oficios, en general, ya desfilaban y bailaban con anterioridad a su participación en las entradas reales. Las celebraciones propias de toda corporación artesanal, ligadas a la festividad del santo adoptado como protector, mostraban a cada oficio en comitiva particular y exclusiva por las calles de Barcelona, mientras que la

\footnotetext{
${ }^{78}$ The civic drama in which they play together constitutes a kind of "material embodiment" of an ideal political order, and by performing in it, they shape their imperfect world into at least a rough approximation of that ideal» (Gordon KIPLING, Enter the King, Pennsylvania, 2001, p.

${ }^{79}$ Para un breve relación de este tipo de noticias a lo largo del siglo XIV véase $\mathrm{M}$. RAUFAST, ¿Un mismo ceremonial para dos dinastías? En cualquier caso, si es posible detectar la presenciá del estamento artesanal en la entrada de la reina María en Perpiñán en 1344, a partir de la descripción que de dicho evento hace la Crónica de Pedro el Ceremonioso: " ... fo rebuda ab molt gran e molt honrada festa e solemnitat que en feren los prohomens de la vila, e tots los oficis, e generalment tota
croniques. Ed. de Ferran SolDEVILA, Barcelona, 1971, p. 1088).

${ }^{80}$ En la entrada de los duques de Gerona en la ciudad: «E entre les altres coses, com fos cosa molt expedient e necessaria, quasi per comencament, empendre e acordar ab los maiorals e promens dels Officis e mesters de la dita ciutat les colors dels vestits lurs per haver diversita de liurees, e axi mateix de metre aquells en orde de lur exida e anada e tornada...» (S. CARRERES, Ensayo de una bibliografía, p. 30 del apéndice documental).

${ }^{81} \mathrm{P}$. IRADIEL, Corporaciones de oficio, pp. 280-281.
} 
procesión anual del Corpus, desde su creación en 1320, aglutinaba los diferentes itinerarios en uno sólo y reunía ya, en desfile común y ordenado, al conjunto del estamento ${ }^{82}$. En la interrelación entre dichos acontecimientos, integrados todos ellos dentro de esa sociedad "teatralizada" de la que hablábamos en el inicio de este artículo, podría hallarse una posible explicación al dilema que plantea el origen de la escenificación artesanal en las entradas reales bajomedievales ${ }^{83}$.

De entre aquellos elementos que configuran dicha escenificación y que, al mismo tiempo, actúan como señas de identidad de cada oficio en particular, esto es, los emblemas, señales y pendones; los entremeses y representaciones; las danzas y bailes; las formas y colores de las vestimentas; $\mathrm{y}$ el orden en que todo ello tiene lugar, nos hemos decantado por abordar únicamente este último aspecto. Dos son básicamente las razones que nos han impulsado a ello: por un lado, la viabilidad práctica de tal elección, fundamentada en la existencia de descripciones ordenadas de desfiles artesanales en la Barcelona del siglo XV; por otro, la posibilidad de relacionar el estudio de la distribución y disposición espacial de los oficios en dichas ceremonias con los signos de jerarquización social y política dentro del estamento artesanal que ya habíamos señalado en el segundo apartado de este artículo.

Disponemos, en este sentido, de cuatro extensas relaciones de entrada real en las que aparecen identificadas las corporaciones y cofradías de oficio que participaron en dichas celebraciones, así como también el orden en que éstas desfilaron ante el monarca, la reina o el primogénito. Tres de ellas - las correspondientes a las entradas de Fernando, primogénito de Juan II, en 1461; Juan de Calabria, primogénito del rey Renato de Anjou, en 1467; e Isabel I, esposa de Fernando II, en 1481- pertenecen a la misma fuente, el Llibre de les Solemnitats de Barcelona, mientras que la restante - el recibimiento al rey Pedro de Portugal en 1464- procede del Dietari o Llibre de Jornades redactado por Jaume Safont ${ }^{84}$.

Hemos desechado la opción de incluir en este grupo el ya mencionado Cronicó de Guillem Mascaró, en el que se describe el desfile artesanal durante

${ }^{82}$ P. BONNASSIE, La organización del trabajo , pp. 125-127. Para una breve pero ilustrativa descripción de una fiesta artesanal, véase $\mathrm{F}$. P [au] VERRIÉl, La fiesta patronal de los freneros en el siglo XV "Barcelona. Divulgación Histórica", V (1948), pp. 65-69. Acerca de la historia de la celebración del Corpus en Barcelona, véase Agustín DURAN ị SANPERE, La fiesta del Corpus, Barcelona, 1943, Igualmente, para una aproximación al mapa viario procesional de la Barcelona bajomedieval, véase Miguel RAUFAST CHICO, Itineraris procesionals a la Barcelona baixmedieval, "Revista d'Etnologia de Catalunya", 29 '(2006) (en vías de publicación).

${ }^{83}$ Puede encontrarse una interesante reflexión sobre los elementos compartidos por las entradas reales y la procesión del Corpus, en cuanto a la participación de los oficios, en Juan OLEZA, Las transformaciones del fasto medieval, en Luis QUIRANTE (ed.), Teatro y espectáculo en la Edad Media, Elche 1992 , p. 55 . En cualquier caso, la proximidad entre ambas ceremonias en la Barcelona bajomedieval no tan sólo es detectable a nivel de itinerarios, escenificación y representaciones: en el último cuarto del siglo XV será cada vez más frecuente que las visitas de la monarquía sean celebradas, además de con los actos correspondientes a la entrada real, con una procesión de Corpus, independientemente de que ésta ya hubiese tenido lugar aquel año. As sucedió en 1477, en la llegada a Barcelona del duque de Calabria (Llibre de les Solemnitats, vol. I, p. 299), o en 1479, en la entrada de Fernando II en la ciudad (Dietari o Llibre de Jornades, p.
.

${ }^{84}$ Para ambas fuentes, véase nota 7. 
la entrada de Martín el Humano, en 1397, en Barcelona, por cuanto su autor únicamente detalla el paso de aquellos oficios que incorporaban algún tipo de entremés o representación a la comitiva ${ }^{85}$. La distorsión que ello supone para la percepción global del acto aconseja utilizar esta relación únicamente a título de fuente complementaria.

El resto de entradas reales que se celebraron, a lo largo del siglo XV, en Barcelona tan sólo ha dejado, en los documentos de la época, la escueta constancia de la existencia del desfile de los oficios. Es el caso de las entradas de Fernando I, en $1412^{86}$; Juan II, en $1458^{87}$; y Fernando II, en $1479^{88}$, o de la simple noticia de su ausencia, como ocurrió en la entrada de Alfonso el Magnánimo, en $1416^{89}$.

Aún así, el nulo detalle con que estas referencias abordan el desfile artesanal, unido a una ambigüedad terminológica común, nos permite plantear dos cuestiones que consideramos necesario resolver previamente al análisis de la disposición escénica de los oficios. Es decir, sería conveniente, antes de conocer en qué orden se desfila, precisar, por una parte, quién desfila exactamente, y por otra, bajo qué concepto lo hace.

El 20 de noviembre de 1458, ultimando la preparación de la entrada de Juan II, los consellers de Barcelona dispusieron, mediante ordenanza leída públicamente por los lugares más señalados del municipio, «que tots los arts, offiçis e confraries de la present ciutat hajen a sseguir lur panó o bandera, segons seran ordonats $»^{90}$. Expresada así, la convocatoria para el desfile de los oficios parecía afectar no únicamente al estamento menestral, sino también a los artistas - recordemos, notarios, apotecarios y médicos, entre otros-e, incluso, a las cofradías de carácter exclusivamente devocional. Una impresión que tiende a corroborar la descripción que hace de dicho desfile el Dietari de la Deputació del General de Cathalunya, al remarcar que, tras el juramento

\footnotetext{
${ }^{85}$ «Nam major pars officiorum tripudiabat, alii incedebant armati, alia pars fecit los jochs següens...» (BC, Ms. 485, f. 271v). Véase, igualmente, nota 58.

${ }^{86} \mathrm{La}$ construcción del catafalco para la familia real en dicha entrada nos permite atestiguar dicho desfile: "...in cadafallo in quo dominus rex et domina regina et eorum primogenitus extiterunt in diebus in quibus intrarunt in dictam civitatem pro mirando de eodem omnia jocha e representationes per diversa officia dicte civitatis ob reverentia e honore predictorum dictorum dominorum factas et facta...» (AHCB, Consellers, Obreria, 1C XIV-4, f. 16v)

${ }^{87}$ «...intra en Barchinona e munta al Catafal e Sitial qui per la Ciutat li era apperellat en la plaça de Fra menors. E aquí jura los privilegis constitucions etc. e vingueren los officis e confraries ab llurs entremeses e balls» (Manual de Novells Ardits, vol. II, p. 294).

${ }^{88}$ Agustí Duran i Sanpere, en la edición del Llibre de les Solemnitats de Barcelona, indica que el manuscrito original conservado en el AHCB presenta, para la relación de la entrada real de Fernando II en 1479, un amplio espacio en blanco -correspondiente al f. 92 V- destinado, en principio, al listado de oficios participantes en dicha ceremonia, y que, sin embargo, nunca fue llurs panons e alguns entremesos sots l'orda següent: Primo, los garbelladós ab llur panó. Item, marinés ab llur panó [...] E passades totes les dites confraries...» (Llibre de les Solemnitats, vol. I, p. 325).

${ }^{89}$ La proximidad de la muerte de su padre, Fernando I, obligó a posponer, en dicha entrada, todo signo de celebración: «...entrà en Barchinona lo senyor rey don Alfonso, qui novamen succehia al rey en Fferrando, pare seu, e vench vestit de gramalla de molada; fonch reebut simplament, sens festa alguna» (Dietari o Llibre de Jornades, p. 7).

${ }^{90} \mathrm{AHCB}, \mathrm{CC}$, Ordinacions originals, 1B XXVI-8, carpeta 494.
} 
del monarca, «vengueren tots los manestrals e artistes ballant uns apres altres» ${ }^{91}$

Sin embargo, por lo que sabemos, el desfile ante el soberano en las ceremonias de entrada real en Barcelona parece privativo del sector artesanal de la población, y en ninguna de las listas disponibles sobre de los componentes de dichos desfiles figura ninguna representación del estamento artista ni tampoco cofradía alguna que no sea de oficio ${ }^{92}$. La repetición de dicha fórmula por parte de los consellers, con motivo de la entrada en Barcelona, en 1461, de Fernando, como primogénito de Juan II, nos ofrece una pista para entrar a valorar la terminología aplicada en estos casos. Los arts, officis $e$ confraries mencionados en la ordenanza del 19 de noviembre de ese año ${ }^{93} \mathrm{se}$ materializan, en realidad, en un desfile formado exclusivamente por los diferentes oficios del estamento artesanal, según la relación de participantes en dicho evento que aparece recogida en el Llibre de les Solemnitats ${ }^{94}$, lo cual nos hace pensar tanto en la ambivalencia de los conceptos utilizados como en la imprecisión con la que éstos podían ser otorgados ${ }^{95}$. Eso es, al menos, lo que parece desprenderse de la comparación entre diversas fuentes a la hora de referirse a un mismo acontecimiento. Así, para 1458, el Manual de Novells Ardits se limita a resaltar la presencia de officis e confraries - sin mención alguna a las arts - en el desfile ante Juan II $^{96}$, mientras que, para 1461, el Dietari de la Deputació especifica que quienes pasaron ante el primogénito fueron les confraries dels manestrals ${ }^{97}$.

A partir de todo ello, es factible determinar que, por encima de la inicial incerteza que pueda generar una terminología confusa, de espíritu probablemente acumulativo antes que diferenciador, el protagonismo en el desfile de los oficios en la entrada real - por lo menos, en la Barcelona de la segunda mitad del siglo $\mathrm{XV}$ - es un asunto que pertenece al estamento artesanal y a sus formas asociativas, quedando al margen tanto los artistas como las cofradías religiosas.

Ahora bien - y ésta sería ya la segunda cuestión que pretendíamos abordar-, no parece tan fácil esclarecer cuál de estas formas asociativas - la corporación de oficio o la cofradía - centra la presencia artesanal en el desfile ante el soberano. Las fuentes de la época siguen siendo, en su conjunto, muy poco precisas también en este aspecto. Así, podemos encontrar, para una misma entrada real —en este caso, la del rey Pedro de Portugal, en 1464-

\footnotetext{
${ }^{91}$ Dietari de la Deputació, vol. II, p. 4.

${ }^{92} \mathrm{Al}$ igual que sucede en Valencia, donde los artistas estaban excluidos de la obligatoriedad de desfilar corporativamente ante el rey, si bien podían hacerlo a título individual. Tal como señala Paulino Iradiel, los barbers de la ciudad, al obtener la categoría de arte en 1481, dejaron de participar en este tipo de actos, mientras que los boticarios, sencillamente, no lo hicieron nunca (P. IRADIEL, Corporaciones de oficio, pp. 283-284).

${ }^{93} \mathrm{AHCB}, \mathrm{CC}$, Ordinacions originals, 1B XXVI-9, carpeta 565.

${ }^{94}$ Llibre de les Solemnitats, vol. I, pp. 238-239.

${ }^{95}$ «Los artesanos del siglo XV tienen dos maneras de denominar a sus asociaciones: confraria por una parte, art u ofici por la otra» (P. BONNASSIE, La organización del trabajo, p. 31).

${ }^{96}$ Manual de Novells Ardits, vol. II, p. 294.

${ }^{97}$ Dietari de la Deputació, vol. II, p. 47.
} 
todo un amplio repertorio de expresiones que van desde arts e officis ${ }^{98}$ hasta confraries $^{99}$, pasando por confraries dels officis ${ }^{100} \mathrm{o}$ tots los officis ${ }^{101}$, lo cual, obligatoriamente, genera una razonable prudencia a la hora de interpretar a qué se refiere cada texto cuando hace uso de uno u otro término.

En realidad, quizá esta dispersión terminológica no hacía más que reflejar la complejidad adquirida por el asociacionismo artesanal en Barcelona a finales de la Edad Media. La cofradía - como ya vimos en su momentohabía llegado a asumir la representatividad social y política de determinados oficios, mientras que permanecía inédita para otras profesiones más modestas. Algunas de éstas últimas, sin embargo, podían integrarse en cofradías de oficios de mayor prestigio, mientras que los miembros de una determinada profesión tenían opción de formar parte, por iniciativa personal y a título meramente devocional, de una cofradía que no fuera la correspondiente a su oficio - -0 , sencillamente, no participar en ninguna-, siempre que ésta no hubiese llegado a fusionar estrictamente la vertiente asociativa con el oficio representado.

En este estado de cosas, es posible considerar que lo que intentaban la mayoría de los textos coetáneos, a la hora de referirse a los desfiles artesanales, no era otra cosa que minimizar la confusión en la que podía derivar toda esta variedad asociativa. La habitual expresión officis $e$ confraries, presente en la mayoría de las fuentes de la época, parecía querer limitar, en su aparente indefinición, las posibilidades de error, y la insistencia de las ordenanzas municipales en acumular conceptos podía responder, por tanto, a un mensaje de clara intencionalidad: todo aquel que desempeñase una profesión artesanal en la ciudad había de tomar parte en el desfile ante el monarca, ya perteneciese a una corporación menestral o fuese miembro de una cofradía de oficio ${ }^{102}$.

¿El oficio como detonante y la cofradía como vehículo expresivo? Nada de ello puede concluirse, a primera vista, a partir de los listados de desfiles artesanales que intentaremos analizar a continuación. En dos de ellos

\footnotetext{
${ }^{98}$ AHCB, CC, Deliberacions, 1B II-16, f. 86v.

${ }^{99}$ Dietari o Llibre de Jornades, p. 187.

${ }^{100}$ Llibre de les Solemnitats, vol. II, p. 277.

${ }^{101}$ AHCB, Consolat de Mar, Deliberacions, I.I-1, f. 179v.

${ }_{102}$ Además de las ya comentadas entradas de Juan II, en 1458, y de su primogénito Fernando, en 1461, han de señalarse también los casos de las entradas del propio Juan II, en 1473 (AHCB, (AHCB, CC, Ordinacions, 1 B IV-10, f. 123v). El más claro ejemplo de todo ello, sin em 1477 lo proporciona la disposición municipal que, en 1473 , establecía la participación, en el lo proporciona la disposicion municipal que, en 1473, establecía la participación, en en recibimiento al primogenito Fernando, de todos aquellos «particulars de quescum dels dits officis, confrares o no confrares» (AHCB, CC, Ordinacions originals, 1B XXVI-14, carpeta 930). Igualmente, disponemos, para Valencia, de una ordenanza municipal que, con motivo de la entrada de la reina Sibila, esposa de Pedro el Ceremonioso, en 1381, indicaba a los artesanos de la ciudad que debían participar en dicha celebración «ensemps ab loffici del qual son depresent, CARRERES, Ensayo de una bibliografia, p. 49 del apéndice documental).
} 
-1461 y 1467- son los oficios quienes desfilan ceremonialmente, mientras que para los otros dos -1464 y 1481- son las cofradías quienes lo hacen.

\title{
4.2. Los oficios y cofradías en escena.
}

El 21 de noviembre de 1461, «vers una hora pessat mig jorn», el infante Fernando, acompañado de su madre, la reina Juana, y de una amplia comitiva, entraba en Barcelona. Tras cruzar los muros de la ciudad, el primogénito al trono de la Corona de Aragón se había dirigido hasta la plaza de Framenors (actual plaza del duque de Medinaceli) para allí, previo encuentro con los consellers, instalarse en el catafalco construido para tal ocasión. Custodiado por la reina, «a la cadira de part dreta», y por los regidores municipales, «a la part esquerra del dit sitial», el hijo de Juan II se había preparado a contemplar el inicio de la celebración que, en su honor, ofrecía la ciudad. En un momento determinado, los pendones y emblemas de las asociaciones artesanales habían abandonado el estatismo en el que habían permanecido durante la larga espera y, en un orden estricto y preciso, habían comenzado a arrastrar tras de sí a la numerosa congregación de menestrales que abarrotaba la plaza. Era el inicio de un desfile que, mediante el color y la música, los elementos espectaculares y la armonía escénica, pretendía honorar al ilustre visitante y contribuir al prestigio del anfitrión, es decir, la ciudad, al mismo tiempo que describía, en su orden de paso ante el primogénito, la imagen de una cierta estructura estamental.

La relación que de toda esta ceremonia se ha conservado en el Llibre de les Solemnitats proporciona la oportunidad de observar, por primera vez, dicho orden:

\begin{abstract}
E stant la dita senyora reyna e senyor primogenit en lo dit cadeffal, los officis que allí foren venguts ab lurs panons e alguns ab entremesos faheren reverencia als dits senyora reyna e primogenit, pessant hu aprés altre denant lo dit cadeffal, axint de la dita plassa, matent-se la via del carrer Ample sots l'ordre següent, ço es, que primer passaren:

... Garbelladors..., marinés..., barqués..., revenedors..., flassadés e mestres de drap de senyal..., boters..., matalaffers..., hostalés..., payers..., corredors de coll..., ortolans..., carnicers..., matrasers.., baynés..., spasés..., fustés e mestres d'axa..., texidors de lana..., cotoners..., merçés..., calsatés..., blanquers..., assehonadors..., texidors de li..., mestres de cases e molers..., boters de fusta grossa..., gerrés e ollers..., fforners e flaquers..., ferrés. ... sabaters..., pallisers..., parayres..., franés..., argenters..., sastres... ${ }^{103}$.
\end{abstract}

Percibimos, de inmediato, que los oficios mencionados en último lugar corresponden - con la excepción de los peleteros- a aquellas cofradías que, en 1455, habían sido distinguidas, por el privilegio real de Alfonso el Magnánimo, con una mayor presencia en el Consell de Cent barcelonés. Las

\footnotetext{
${ }^{103}$ Llibre de les Solemnitats, vol. I, pp. 258-259. Hemos reproducido aquí únicamente los nombres de los oficios, tal como aparecen en el texto, eliminando aquellas otras referencias, como emblemas o entremeses, que acompañan la larga enumeración.
} 
mismas que, a lo largo del siglo XIV y la primera mitad del XV, se habían significado con más fuerza en la representación política del estamento artesanal en el gobierno municipal. Si consideramos que, tanto en las procesiones del Corpus como en las entradas reales, la situación respectiva, al final de las comitivas, de la forma sagrada y del rey era la que determinaba el orden de precedencia de los participantes - esto es, en un sentido inverso al del orden de la marcha, concediendo mayor importancia y prestigio a aquéllos que ocupaban los últimos lugares del desfile ${ }^{104}$-, podremos convenir que, además de mostrar el espectro de la actividad profesional artesanal en Barcelona, el desfile de los oficios en la entrada del infante Fernando traducía visualmente la jerarquización social del estamento.

Una jerarquización que, en sus extremos, aparece prácticamente fosilizada, puesto que no únicamente se repite en el resto de relaciones de entrada que poseemos para el siglo XV, sino que es perceptible, a través de otras ceremonias cívicas, desde finales del XIV hasta bien entrado el siglo XVI. Así, sastres, plateros, freneros, pelaires, peleteros, zapateros y herreros ocupan permanentemente, a lo largo de todo este amplio arco temporal, los lugares de privilegio en toda formación de desfile, ya se trate de la convocatoria de la hueste de la ciudad, como en $1395^{105}$, o de la procesión del Corpus, como en $1520^{106}$, mientras que los cribadores y, especialmente, las diversas profesiones relacionadas con el mar (marineros, barqueros, etc.) se ven, de manera invariable, relegados a las posiciones de menor rango ${ }^{107}$.

Entremedio, una escala variopinta de oficios que, por lo menos entre 1461 y 1481, tiende a permanecer inamovible. ¿Se trata del reflejo de una estabilidad socio-profesional dentro del artesanado barcelonés o, por el contrario, no es otra cosa que la compensación escénica destinada a esconder una realidad mucho más dinámica? ¿Pesa más, en estos rituales cívicos, su capacidad para expresar jerarquías sociales y políticas ${ }^{108}$, o más bien lo que prima en ellos, por encima de todo, es la recreación de una cierta "ficción de inalterabilidad" "09, basada en la tradición y en criterios que - como sería el

\footnotetext{
${ }^{104} \mathrm{~A}$ diferencia de lo que ocurría, por ejemplo, con la convocatoria de la hueste urbana en Barcelona, donde la presencia de la bandera de la ciudad encabezando la formación exigía una disposición en orden deçrẹciente, figurando en primer lugar, dentro del estamento artesanal, los oficios con mayor prestigio e importancia.

${ }^{105} \mathrm{AHCB}, \mathrm{CC}$, Ordinacions, 1B IV-3, ff. 30v-36r. 1395, noviembre, 23. Barcelona.

${ }^{106}$ AHCB, CC, Ordinacions, 1B IV-12, ff. 178v-179v. 1520, junio, 20. Barcelona.

${ }^{107}$ Algo que también es posible concluir a partir de la seleccionada relación de oficios que se incluye en el Cronicó de Guillem Mascaró, puesto que, a pesar de señalar únicamente aquéllos que habían realizado algún tipo de representación o entremés ante Martín el Humano en su mientras Barcelona en 139, freneros y plateros siguen siendo mencionados en ultimo lugar, mientras que barqueros y homines maris parecen ser igualmente los encargados de abrir la Cronicó es la siguiente: barqueros, marineros, curtidores, maestros de obra, ropavejeros, algodoneros, carpinteros, freneros y plateros.

${ }^{108}$ «Le rituel public permettait aux corporations de confirmer leur rôle dans le système politique et dans la hiérarchie sociale» (Katharina SIMON-MUSCHED, Les documents normatifs et LAMBRECHTS; J. P. Sosson (eds.), Les métiers au Moyen Age, p. 320.

${ }^{109}$ E. MuIR, Fiesta y rito, p. 298.
} 
de la antigüedad de cada oficio- reducen las posibilidades de modificación de lo ya establecido ${ }^{110}$ ?

Contestar estas preguntas exigiría un estudio mucho más profundo - tanto de la evolución socioeconómica del sector artesanal como del conjunto de valores que inciden en la disposición escénica de los oficios en desfile- del que estamos en condiciones de ofrecer aquí. No es descabellado suponer, sin embargo, que en todo este entramado de relaciones intervenían - pero seguimos sin saber exactamente en qué grado- los mismos factores que contribuían a determinar la intensidad de la presencia política de las diferentes corporaciones artesanales en el Consell de Cent barcelonés ${ }^{111}$. De esta manera, la ya señalada antigüedad del oficio, el número de miembros de la cofradía o el peso social y económico de la profesión podían ser argumentos válidos a utilizar, en unos casos para respetar un orden previo, en otros para plantear su revocación.

En este sentido, la descripción que ha quedado de la celebración que acompañó la entrada en Barcelona, en 1464, del rey Pedro de Portugal provoca una cierta incertidumbre cuando se estudia su contenido. A ojos de Jaume Safont, que recogió la ceremonia en su dietario particular - paralelo al que desarrollaba de forma cotidiana, en tanto que escribano de la institución, para la Diputación del General- las cofradías y oficios artesanales de la ciudad desfilaron ante el monarca en el orden siguiente:

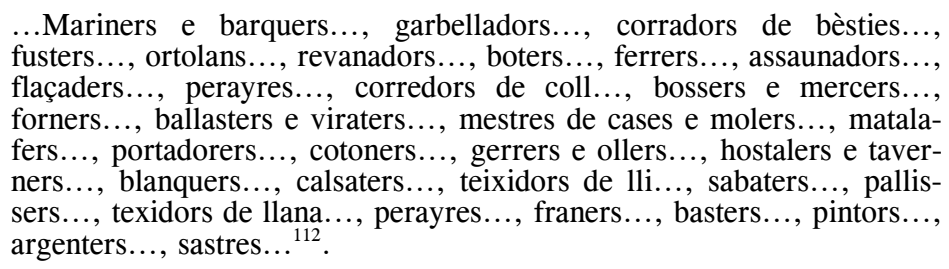

Aunque el orden de precedencia presenta una estructura básica muy similar a la de 1461, con los sastres, plateros, freneros, pelaires, peleteros y zapateros acaparando nuevamente los lugares de honor, y los marineros, barqueros y cribadores asumiendo el papel más modesto en la comitiva, en el interior del desfile parece desatarse una verdadera convulsión. Los puestos se intercambian y se alternan (los calceteros y los curtidores; los propios cribadores y los barqueros); experimentan fluctuaciones notorias (los manteros

\footnotetext{
${ }^{110}$ En 1512 , un conflicto de precedencia entre las cofradías de los zurradores y los curtidores de la ciudad de Zaragoza obligo a las autoridades municipales a fallar en favor de los primeros, ordenando que «la bandera de los çurradores et los ditos çurradores hayn de ir e vayan a perpetuo
en la dicha procession de corpus Christi mas cagueros que no la dicha bandera de los dichos en la dicha procession de corpus Christi mas çagueros que no la dicha bandera de los dichos blanqueros, por ser la confraria e officio de curradores muy antiguo" (Archivo Municipal de Zaragoza, Actos Comunes, 1512, f. 83v. Transcrito en María Isabel FALCÓN PÉREZ, Las Cofradias artesanales de la Edad Media. Aspectos religiosos y sociales, en M. BARCELO (ed.),
La manufactura urbana, p. 210, nota 30). ${ }^{111}$ Véase p. 660.

${ }^{112}$ Dietari o Llibre de Jornades, pp. 187-189. Hemos extraído del texto original, al igual que en la entrada del infante Fernando en 1461, únicamente los nombres de los oficios participantes.
} 
$\mathrm{y}$, especialmente, los colchoneros incrementan su prestigio en el desfile; los carpinteros y los zurradores parecen disminuirlo); e incluso ofrecen sorprendentes e inexplicables diferencias: los tejedores de lana se instalan entre la élite artesanal, mientras que los herreros parecen quedar excluidos de su privilegiada posición para pasar a ocupar una humilde plaza en el inicio del desfile.

Todas estas variaciones, difíciles de entender en un período de tan sólo tres años, quizá podrían ser achacables a las particulares circunstancias que rodearon la celebración de la entrada de Pedro de Portugal ${ }^{113}$, o al significativo hecho de haber tenido lugar en un época de tanta inestabilidad como la que caracterizó al período de la Guerra Civil catalana, si no fuera porque, pocos años después, en la entrada del duque de Calabria en 1467, aún en pleno conflicto bélico y también bajo condicionantes muy particulares ${ }^{114}$, el desfile de los oficios - por lo menos así lo indica el Llibre de les Solemnitats - volvió a adquirir la misma e idéntica configuración que había tenido en 1461.

¿Se trata de un asunto que tiene que ver más con la fuente de los datos que con una real reorganización escénica del artesanado en Barcelona? En cualquier caso, la aparente imprecisión del Dietari en el orden del desfile contrasta vivamente con el detalle con el que describe el paso de sus integrantes. Así, a diferencia de la parquedad característica de las relaciones del Llibre de les Solemnitats, el escribano Safont muestra a los marineros y barqueros pasando ante el monarca en compañía de sus esclavos, que tenían «pintades les cares en dues eguals parts, ço és, la una galta de blanch e l'altra de vermell, l'altre aportava la una galta verda e l'altra blava ${ }^{115}$, y precedidos por la figura de un gran dragón que, lanzando fuego por la boca, intentaba abrirse paso entre el numeroso público que se congregaba en las calles para asistir al desfile de los oficios y sus entremeses. Tenemos también la ocasión de ver qué hay más allá de la simple denominación habitual de la cofradía y comprobamos, por ejemplo, cómo los freneros son, en realidad, «los franers, basters, pintors e altres de lur confraria» ${ }^{116}$, lo cual nos induce a sospechar

\footnotetext{
${ }^{113}$ Una celebración que tal como se relata en el Llibre de les Solemnitats, no se desarrolló en un único día, sino que quedó fragmentada en diversos actos -entre los cuales, el desfile artesanala lo largo de diversas jornadas, entre el 21 y el 26 de enero de 1464 . Véase Llibre de les
Solemnitats, vol. I, pp. 274-277.

${ }^{114} \mathrm{El}$ primogénito del rey Renato de Anjou hubo de esperar tres días hasta que la ceremonia destinada a solemnizar su entrada en Barcelona estuvo preparada. Durante ese tiempo permaneció recluido dentro de la ciudad, en la casa del tintorero Francesc Estaper. Llegado el en la ciudad por el portal asignado a tal efecto. Véase Llibre de les Solemnitats, vol. I, pp. 286293.

${ }^{115}$ Dietari o Llibre de Jornades, p. 187. Dentro del oficio de los barqueros no existían los obreros, siendo su trabajo desempeñado por mano de obra esclava. Ello explica, hasta cierto punto, la presencia de esclavos en el desfile artesanal. Para el tema de la esclavitud en el mundo laboral de la Barcelona bajomedieval, véase P. BONNASSIE, La organización del trabajo, pp. 97103.

${ }^{116}$ Dietari o Llibre de Jornades, p. 188. Esta misma cofradía, en la convocatoria de la hueste de la ciudad, en 1395 , aparece desglosada de la siguiente forma: ifreners, sellers, pintors, cofrers e basters, e tots altres qui hajen acostumat d'anar ab ells» (AHCB, CC, Ordinacions, 1B IV-3, f.32r).
} 
que, tras los listados de oficios participantes en las ceremonias de entrada real se esconde, de hecho, un mundo mucho más dinámico y complejo del que éstos son capaces de mostrar. Finalmente, tenemos el privilegio de asistir al desplegamiento corporativo de los plateros, quienes, en un alarde de coherente ostentación, se exhibieron «ab robes folrades de pell de mars, ab collars e cadenes d'argent e molts qui aportaven de richs fermals, uns en los pits, altres en los barrets; e ultra açò vengueren los propdits ab les robes e ab les calses brodades d'argenteria ${ }^{117}$. Tras ellos, los sastres cerraban el desfile artesanal, ocupando el lugar más destacado para un oficio en este tipo de ceremonias, esto es, «al detraç de tots, pus prop del senyor rey».

Tal como ya hemos indicado, el relato de la entrada que, en 1467, tres años más tarde de la efectuada por el rey Pedro de Portugal, realizó en Barcelona Juan de Lorena, duque de Calabria, en calidad de primogénito del nuevo monarca, Renato de Anjou (elegido por el Principado tras el fallecimiento, en 1466, de Pedro de Portugal), recomponía de nuevo la disposición escénica de los oficios artesanales y la mostraba literalmente mimética de la que había tenido lugar en 1461, con motivo de la entrada del infante Fernando:

E stant axí, lo dit senyor en lo dit cadaffal, los officis, qui allí eren venguts $\mathrm{ab}$ lurs penons e entremesos, faeren reverencia al dit senyor, passant hu aprés altre devant lo dit cadaffal [...] Los dits officis, per orde, son los següents:

...Garbelladós..., mariners..., barquers..., revenedors..., flaçadés e mestres de drap de senyal..., botés de fusta prima..., mathalafers..., hostalers..., payers..., corredós de coll..., ortolans..., carnicers..., matrasers..., spasés..., fustés e mestres d'axa..., texidós de drap de lana..., conthorners..., mercers..., calsaters..., blanquers..., asaonadors..., texidós de lli..., mestres de cases e molers..., boters de fusta grossa..., gerrers e ollers..., fforners e fflaquers..., fferrers..., sabaters..., pallicers..., perayres..., ffreners..., argenters..., sastres.... ${ }^{118}$.

Un orden que, en 1481, en ocasión de la primera visita a la ciudad de la reina Isabel, volvería a articularse exactamente igual ${ }^{119}$, viniendo a confirmar la aparente inmutabilidad de la jerarquía establecida dentro del estamento artesanal a lo largo del siglo $\mathrm{XV}^{120}$.

\footnotetext{
${ }^{117}$ Dietari o Llibre de Jornades, p. 188.

${ }^{118}$ Llibre de les Solemnitats, vol. I, pp. 292-293. Al igual que en las anteriores relaciones de 1461 y 1464 , reproducimos tan sólo los nombres de los oficios, tal como aparecen mencionados en el texto.

${ }^{119}$ Ibídem, pp. 339-340. Con una resaltable novedad, sin embargo. El texto señala explícitamente la ausencia en el desfile de los calceteros: «no anaren». ¿Era la manera de expresar, por parte de dicha cofradía, su malestar ante el hecho - ya comentado en el inicio de este artículo- de seguir careciendo de representación política en el Consell de Cent?

${ }^{120}$ Una inmutabilidad que alcanza, como mínimo, hasta el primer cuarto del siglo XVI. El desfile artesanal en la entrada de Carlos I, en 1519, en Barcelona ofrece leves variaciones respecto del esquema habitual del siglo XV. Sin embargo, para la entrada de Felipe II en la ciudad, en 1564 , el panorama es sustancialmente diferente, y, aunque sastres, plateros, freneros y zapateros continúan manteniendo su privilegiada jerarquía, ahora son los pelaires, carpinteros y curtidores quienes ocupan los lugares de menor prestigio en la comitiva. Para dichas relaciones véase Llibre de les Solemnitats, vol. I, pp. 398-399, y vol. II, pp. 10-11, respectivamente.
} 
De hecho, se trata de una constatación no únicamente aplicable a la Barcelona bajomedieval, y que tiende a coincidir, por ejemplo, con lo ya observado por Paulino Iradiel en relación a la ciudad de Valencia. Para dicho autor, el orden de los «oficios en procesión» permaneció fijado desde el último cuarto del siglo XIV hasta el final de la Edad Media. Dentro de esta permanente jerarquía escénica - reflejo de la antigüedad y del prestigio social y económico de cada oficio-, los pelaires, los curtidores, los plateros y los sastres ocuparon siempre los lugares de privilegio, mientras que los carniceros, correeros y aluderos se encargaron de abrir, una y otra vez, los desfiles del artesanado valenciano en las entradas de la familia real ${ }^{121}$.

Ahora bien, además de los valores mencionados, ¿era capaz dicho orden de reflejar el status político adquirido por las diferentes cofradías? Ya hemos visto cómo existía una clara correlación entre los lugares de privilegio en el desfile artesanal y la élite de los oficios con participación en el Consell de Cent, de tal manera que sastres, plateros, freneros, pelaires, zapateros y herreros manifestaban una visible jerarquía dentro del estamento artesanal, tanto a través de sus representantes en la Casa de la Ciudad como de su escenificación corporativa en las ceremonias cívicas barcelonesas.

Pero incluso, si nos atreviéramos a ir un poco más lejos, tal vez podríamos hacer extensiva dicha relación a la totalidad del conjunto procesional. Así, tomando como referencia la mencionada entrada real del duque de Calabria en 1467, y comparando el listado de cofradías y oficios que desfilaron en aquella ocasión con la composición del Consell de Cent en dicha fecha $^{122}$, nos encontramos con un contraste revelador: de las 16 cofradías que figuraron en la primera mitad de la comitiva, sólo cinco (toneleros de fusta prima, ropavejeros, hortelanos, carpinteros y tejedores de lana) tenían representación en el Consell de aquel año, mientras que de las 17 corporaciones que lo hicieron en la segunda mitad, es decir, en posiciones de mayor prestigio, únicamente tres (horneros, toneleros de fusta grossa y calceteros) estaban ausentes de la contribución artesanal al gobierno de la ciudad en aquel preciso momento.

Ello nos hace pensar que, sin llegar a ser una plasmación exacta, la puesta en escena de las cofradías y oficios artesanales en las entradas reales celebradas en la Barcelona del siglo XV tendía a reproducir la jerarquía política existente en el interior del estamento, de la misma manera que la representación en el gobierno municipal era, en cierta forma, una consecuencia del prestigio social de cada oficio, y éste, a su vez, se alimentaba de aquellos rituales públicos que lo hacían visible, en lo que venía a ser un complejo, cíclico e inacabable juego de interacciones en el cual, al igual que

${ }^{121} \mathrm{P}$. IRADIEL, Corporaciones de oficio, pp. 282-283. Iradiel utiliza, para su argumentación, las relaciones de desfiles de oficios que aparecen recogidas en S. CARRERES, Ensayo de una bibliografia - entrada en Valencia de los duques de Gerona en 1373 (pp. 30-31 del apéndice documental); entrada de Juan I en 1392 (pp. 61-62 del apéndice documental) - y en Dietari del la ciudad de Juan II (pp. 225-227).

${ }^{122}$ AHCB, CC, Deliberacions, 1B II-17, f. 157r-157v. 
sucedía en otros niveles de la sociedad urbana medieval, el ceremonial, más que ser una extensión representativa de una determinada realidad, contribuía a crearla ${ }^{123}$.

\author{
5. EL ESCENARIO TENSIONADO: \\ CONFLICTOS EN TORNO A LA PARTICIPACIÓN \\ DE LOS OFICIOS EN LAS CEREMONIAS URBANAS
}

Aprés del duch anaven tots los órdens, cascú ab un ciri ençés en la mà. Aprés venien tots los menestrals, cascun ofici ab sa lurea que feta havien. E fon molt gran divís entre los oficis, que jo pensí que los uns ab los altres se matarien.

- ¿Sobre quina causa fon aquexa divisió? - dix l'ermità.

-Senyor - dix Tirant-, jo us ho diré. Entre los ferrés e los texidós fon lo divís, car los texidós de lí deyen que devien precehir als ferrés, e los ferrés deyen lo contrari, que ells devien haver la honor dels texidós. Ajustaren-se en cascuna part passats X mília hòmens. $\mathrm{E}$ los juristes foren causa de tot açò, car al·legaven per part dels texidós que no's podia dir missa ni consegrar lo preciós Cors de Jesucrist sens drap de li; e los juristes per part dels ferrés al-legaven que primer fon l'ofici de ferrer que no de texidor, per quant lo teler del texidor no podia ésser fet sens ferramenta, per què era provat l'ofici de ferrés ésser més antich e deure precehir als texidós ${ }^{124}$.

De la misma forma que la lectura de la documentación medieval de origen institucional, y especialmente de los textos de carácter normativo, conlleva el peligro de ofrecer una imagen, en ocasiones, tentadoramente estable de la estructura y funcionamiento de las asociaciones artesanales - tal como han prevenido, entre otros, Jacques Heers ${ }^{125}$ o Jean-Pierre Sosson ${ }^{126}-$, también los testimonios que las crónicas, dietarios y documentación oficial de la época proporcionan de las ceremonias y celebraciones cívicas urbanas son capaces de crear representaciones idealmente armoniosas de la participación de cofradías y oficios en dichos eventos.

Y sin embargo, lo que Tirant, en el fragmento que hemos extraído de la novela de Joanot Martorell, relata haber visto no es ningún hecho excepcional, e incluso es más que probable que el propio autor contemplara o conociera en vida algún episodio semejante a través de su experiencia personal, ya fuera en su cercana Valencia o en las cortes de Alfonso el

\footnotetext{
${ }^{123}$ Una idea recurrente en la historiografía ceremonialista (véase C. GAUVARD, Le rituel objet d'histoire), y que enlaza, en çierta manera, con las teorías del antropólogo Clifford Geerd rituel, sobre el "Estado-teatro": "Una incineración real no era un eco de una política que tenía lugar en algún otro sitio. Era una intensificación de una política que tenía lugar en todas partes» (Clifford GEERTZ, Negara. El Estado-teatro en el Balí del siglo XIX, Barcelona, 1999, p. 200).

${ }^{124}$ Joanot MARTORELL, Tirant lo Blanc (edición de Albert G. HAUFF), 2 vols., Valencia, 1990, vol. I, p. 67

${ }^{125}$ Jacques HEERS, Les métiers et les fêtes “médiévales" en France du Nord et en Anglaterre, «Revue du Nord», 218 (1973), p. 198

${ }^{126}$ «...toute lecture des status de métier risque d'appauvrir le réel car ne donant qu'une image non pas erronée, mais tronquée, voire incompréhensible du monde du travail» (Jean-Pierre SOSSON, Les métiers: norme et réalité. L'exemple des anciens Pays-Bas méridionaux aux XIV et $X V^{e}$ siècles, en P. LAMBrechts; J. P. SOSSON (eds.), Les métiers au Moyen Age, p. 348).
} 
Magnánimo, en Nápoles, y del príncipe de Viana, en Barcelona ${ }^{127}$. De hecho, se trata de una realidad que afecta al conjunto de la sociedad urbana bajomedieval, situando a todo acto público colectivo entre el efecto cohesionador que éste pueda tener sobre la comunidad y su misma capacidad para despertar la intensa competitividad subyacente en el interior de la estructura de la universitas ${ }^{128}$. Un fenómeno común que recorre prácticamente todos los estadios del mundo urbano y que implica tanto a instituciones, ya sean laicas o religiosas, como a estamentos, desde las más altas instancias del poder municipal hasta la más modesta de las agrupaciones de oficio.

Los ejemplos de conflictos y enfrentamientos a causa del lugar ocupado en un desfile procesional son relativamente numerosos, y el cuidado con el que se intentaba prevenirlos o evitarlos es una señal más de la importancia que se concedía al significado de la ordenación escénica de los participantes en dichas celebraciones ${ }^{129}$. Bajo esta premisa, una ceremonia pública será siempre el resultado de la fricción entre un aparente orden colectivo integrador - en tanto que intento de reconstrucción ideal de una realidad - y los intereses diversos y no siempre coincidentes de sus participantes.

Así, para la Barcelona del siglo XV, conocemos disputas entre la ciudad y la corte real, con motivo de la ordenación de las personalidades presentes en las exequias fúnebres de Juan II en $1479^{130}$; discusiones entre los consellers y los diputados de la Generalitat, a causa de colocación de los porters de esta última institución en cabeza de la comitiva que había de desplazarse hasta la Catedral durante la ceremonia por la muerte de la reina Leonor en $1436^{131}$; protestas del estamento mercader por no figurar bajo el mismo pendón que los ciudadanos honrados en la hueste de la ciudad convocada en $1425^{132}$; o pleitos entre órdenes religiosas -agustinos y carmelitas- originados por la situación respectiva de sus miembros en las procesiones organizadas por la ciudad ${ }^{133}$.

En este universo ordenado y, al mismo tiempo, descompuesto, en el que cualquier variación en el ritual celebrativo era susceptible de ser

\footnotetext{
${ }^{127}$ Acerca de la estancia de Joanot Martorell en la Barcelona del siglo XV, véase Jaume TURRÓ TORRENT, Una cort a Barcelona per a la literatura del segle XV, «Revista de Catalunya», 163 (2001), pp. 97-123, y en concreto las pp. 117-121.

${ }^{128}$ Véase, para una percepción de la fiesta del Corpus como foco de tensión y conflicto social, M. JAMES, Ritual, Drama, pp. 18-19.

${ }_{129}$ «L'ordre seguit és, molt important. En una societat avesada a les processons, tothom vetlla molt el lloc ocupat i se'n preoçupa prou de no veure's rellegat tot essent sobrepassat per algú considerat inferior» (F. SABATÉ, Lo senyor rei és mort!, p. 55).

${ }^{130}$ Llibre de les Solemnitats, vol. I, p. 306.

${ }^{131}$ Ibídem, p. 69.

${ }^{132}$ C. BATLLE, La crisis social y económica, vol. I, pp. 137-138.

${ }^{133}$ Rúbriques de Bruniquer. Ceremonial dels Magnifichs Consellers y Regiment de la Ciutat de Barcelona, 5 vols. Colecció de Documents Historichs Inèdits del Arxiu Municipal de la Ciutat de Barcelona, 1912-1916, vol. I, p. 286. Las exequias por la muerte de la reina Violante, en 1431, mostraron igualmente la antigua discordia existente entre los conventos femeninos de Valldonzella y de Jonqueres en este aspecto. Véase, para dicho conflicto, Llibre de les Solemnitats, vol. I, pp. 50-51.
} 
interpretada en términos tanto sociales como políticos, sorprende, sin embargo, no encontrar apenas huellas palpables de conflictividad ceremonial por lo que respecta al estamento artesanal barcelonés. Mucho más cuando dicha conflictividad, además de ser detectable en otras ciudades, tanto peninsulares como europeas, parece intuirse a partir de la relación cotidiana entre las cofradías y oficios de la Barcelona bajomedieval ${ }^{134}$.

Ya hemos visto como los zurradores y curtidores de Zaragoza hubieron de zanjar sus diferencias sobre el orden de precedencia en la procesión del Corpus de 1512 con la intermediación de las autoridades municipales ${ }^{135}$. Una situación que nos aparece repetida tanto en la Tarragona de inicios del siglo $\mathrm{XV}$, a través de las discrepancias surgidas entre los hortelanos, los herreros, los sastres y los zapateros de la ciudad en torno a los lugares de privilegio en la comitiva artesanal presente en el Corpus ${ }^{136}$, como en la Valencia bajomedieval, de la mano del pulso mantenido entre zapateros y carpinteros para obtener la preeminencia en los desfiles públicos ${ }^{137}$, o en la York inglesa, donde, entre 1482 y 1493, zapateros y tejedores dirimieron una inacabable disputa acerca de quién debía mantener la precedencia en la procesión del Corpus, y en la cual llegaron a intervenir tanto la monarquía como las autoridades de la ciudad ${ }^{138}$.

El papel determinante de los regidores municipales, tanto en la resolución de este tipo de situaciones como en la elaboración de las medidas destinadas a impedirlas, es el que nos permite, en cualquier caso, disponer de alguna referencia tardía sobre la existencia de posibles divergencias y confrontaciones de carácter ceremonial en el interior del estamento artesanal de la Barcelona bajomedieval. Fue, precisamente, con la intención de «cessar tota natura de disordres y diferències que entre los dits officis e confreries se porien seguir per causa de les precedències o graduaments de aquells, segons que en lo passat és stat vist, si present no y era» que, en 1520 , los consellers decidieron fijar y establecer, mediante ordenanza pública, el orden exacto que cada cofradía u oficio había de ocupar en la procesión del Corpus ${ }^{139}$.

Nos gustaría poder confirmar en la práctica la razonable sospecha de que todos estos síntomas de conflictividad generados en torno a la periódica celebración anual de la fiesta del Corpus son igualmente extrapolables a las ceremonias, mucho más esporádicas, de entrada real. Sin embargo, las

\footnotetext{
${ }^{134}$ Para Pierre Bonnassie, las agrupaciones artesanales barcelonesas de finales de la Edad Media tienden a ignorarse unas a otras: «Si se relacionan, es para enfrentarse en procesos y diferencias de todo género» (P. BONNASSIE, La organizacion del trabajo, p. 63).

${ }^{135}$ Véase nota 110.

${ }^{135}$ Francesc CORTIELla I ÒDENA, Una ciutat catalana a darreries de la Baixa Edat Mitjana: Tarragona, Tarragona, 1984, p. 316.

${ }^{137}$ L. PILES, Estudio sobre el gremio de zapateros, p. 115.

${ }^{138}$ Alexandra F. JOHnston, The Guild of Corpus Christi and the Procession of Corpus Christi in York, «Mediaeval Studies», 38 (1976), p. 382. La mediación en el conflicto origino, a su vez uno nuevo entre el abad designado por el rey para intervenir en el asunto y el consejo municipa de York al considerar éste ûttimo que la resolución del problema era competencia exclusiva de la ciudad y que la interferencia del mencionado abad atentaba contra las franquicias y libertades del municipio.

${ }^{139}$ AHCB, CC, Ordinacions, 1B IV-12, ff. 178v-179v.
} 
noticias de las que disponemos hasta la fecha resultan insuficientemente explícitas y poco concluyentes al respecto. Así, el ya conocido conflicto de los calceteros barceloneses y la ausencia de dicha cofradía en el desfile artesanal organizado en la entrada de la reina Isabel en 1481 parecen, en realidad, un asunto que concernía más a la representación política de la corporación que no estrictamente a un problema de precedencia o graduación escénica. Y, por añadir algún otro ejemplo aislado, la negativa de los plateros a desfilar en 1564, en la entrada real de Felipe II en Barcelona, argumentando carecer de pendón, quizá podría esconder algún tipo de desavenencia institucional que, por el momento, somos incapaces de precisar ${ }^{140}$.

Queda, como último recurso, la posibilidad de acudir a aquellos gestos institucionales de carácter preventivo, y también coercitivo, con los cuales los ediles municipales intentaban garantizar al máximo el correcto desarrollo de las ceremonias de entrada real, para encontrar signos de potenciales desencuentros con el estamento artesanal. Si, en Valencia, los jurados consideraban imprescindible acordar conjuntamente con los oficios el orden en que éstos habían de desfilar en las recepciones reales «per esquivar entre aquells torbament e discordia ${ }^{141}$, o estipulaban que cualquier cambio en los emblemas y en los trajes identificativos de las cofradías había de serles notificado y obtener su aprobación «per no torbar o multiplicar una matexa divisa, liurea o color ${ }^{142}$, en Barcelona, los consellers determinaban la cuantía de las penas económicas - «sots ban de $\mathrm{C}$ sous a quescun qui contrafaja»con las que se castigaba la negativa a participar en la celebración de la entrada real $^{143}$, o remitían a aquellas multas ya contempladas en las propias ordenanzas de cada cofradía - «sots los bans ja statuïts per ordinacions dels dits arts e officis»- para situaciones de este tipo ${ }^{144}$, y prohibían toda actividad laboral con el fin de asegurar la asistencia al evento ${ }^{145}$.

\footnotetext{
${ }^{140}$ Finalmente, los plateros hubieron de desfilar, obligados por los consellers, y así parecieron manifestarlo en su forzada comparecencia pública: «los fonch manat per dits honorables consellers que: $y$ anassen, e axí hy anaren, ab ses capes abrigats, ab molta gravetat, sens fer joch algú» (Llibre de les Solemnitats, vol. II, p. 11).

${ }^{141}$ Entrada de los duques de Gerona en 1373 (S. CARRERES, Ensayo de una bibliografía, p. 30 del apéndice documental)

${ }^{142}$ Entrada de Juan I en 1392 (Ibídem, p. 58 del apéndice documental).

${ }^{143}$ Entrada de Juan II en 1458 (AHCB, CC, Ordinacions originals, XXVI-8, carpeta 494). Por lo que respecta a Valencia, los jurados, con motivo de la entrada real de Fernando I en 1413 , dispusieron penalizaciones que afectaban tanto a los artesanos en particular como a cada cofradía en su conjunto: «manen a tots maiorals e cap dofficis e a cascun daquells en nom e loch de cascun offici e mester que sien estat amprats e pregats fer preparatoris a la dita beneventurada festa en pena de doents florins dor per cascun offici e mester e a cascun singular dels dits officis e menestrals en pena de vint florins dor per cascun daquells contrafaents e no obedients» (S. CARRERES, Ensayo de una bibliografía, pp. 81-82 del apéndice documental).

${ }^{144}$ Entrada del infante Fernando en 1461 (AHCB, CC, Ordinacions originals, XXVI-9, carpeta 565). A título de ejemplo, la cofradía de los herreros de Barcelona, por privilegio de Martín el Humano concedido en 1401, tenía establecida una pena de diez diners para todo aquel que no acudiera a las reuniones convocadas por los cónsules de dicha asociación (F. de BOFARULL, Gremios y cofradías, CODOIN, vol. XLI, p. 205).

${ }^{145}$ Entrada de Martín el Joven, rey de Sicilia y primogénito de Martín el Humano, en 1405: «E més avant preguen tothom generalment que 1 dit dimenge, el diluns, el dimarts següents, tothom que port dol pos aquéll e faça festa los dits diluns e dimarts, sens obrir obradors e parar taules e fer altre fahena, per honor e reverència del dit senyor rey de Sicília,
senyor rey» (AHCB, CC, Ordinacions originals, 1B XXVI-2, carpeta 78).
} 
Precauciones, disposiciones preventorias, negociaciones y acuerdos previos, medidas punitivas y obligaciones taxativas que nos hablan, en definitiva, del rostro menos visible de cualquier celebración colectiva y que, de hecho, tienen por objetivo disimular, precisamente, todas aquellas grietas que pudieran llegar a deslucir la brillantez del evento $\mathrm{y}$, en consecuencia, debilitar el mensaje que éste había de transmitir. Por debajo de todo ello, un cúmulo de tensiones latentes configuran una realidad mucho más descompasada y arrítmica, incapaz de adaptarse al paso ceremonial del desfile o de la procesión, y cuyo conocimiento es imprescindible para poder entender la función y el significado de todo ritual urbano.

\section{CONCLUSIÓN}

Es posible deducir, a partir del encuentro entre la organización artesanal de la Barcelona bajomedieval y las celebraciones de carácter colectivo que tenían lugar en la ciudad en esa época, una evidente relación entre la presencia escénica de los diferentes oficios y cofradías y el papel jugado por éstos a nivel social o político. La participación de las agrupaciones menestrales en este tipo de actos y, en concreto, en las ceremonias de entrada real, no se limitaba únicamente a dejar constancia del peso del estamento artesanal en la realidad urbana del municipio, sino que también reflejaba, invariablemente, la jerarquización que lo estructuraba. El orden ocupado en el desfile con el que el artesanado barcelonés honoraba -en una tradición ya plenamente establecida desde finales del siglo XIV - la primera visita del monarca a la ciudad se convertía, así, para cada cofradía o corporación de oficio, en la oportunidad de visualizar su posición en dicha jerarquía.

Los oficios que ocupan los lugares de mayor prestigio en dichos desfiles - sastres, plateros, freneros, pelaires, peleteros, zapateros y herreros-son, básicamente, los mismos que cuentan con un mayor grado de representación política en el gobierno de la ciudad, a través de una presencia permanente y más numerosa que, de hecho, se remonta a la misma creación, en 1257, del Consell de Cent barcelonés. Dicha preeminencia - contrastada, en el otro extremo del escalafón, por la mucho más modesta consideración social de los cribadores y los barqueros, relegados a las posiciones menos destacadas del desfile - perduró a lo largo de todo el siglo $\mathrm{XV}$, en una constante que afectaba no tan sólo las ceremonias de entrada real, sino también a cualquier evento cívico colectivo, ya se tratase de la celebración de la fiesta del Corpus o de la convocatoria de la hueste del municipio.

El estudio de esta relación entre el artesanado de la Barcelona bajomedieval y su escenificación ceremonial se ve, sin embargo, lastrado por las graves lagunas historiográficas que, para esta ciudad, presentan ambos temas. Carecemos de un conocimiento sustancial acerca del proceso de gestación y posterior evolución tanto de las formas asociativas de los oficios menestrales como de las celebraciones destinadas a solemnizar la entrada de los soberanos en Barcelona, y tampoco disponemos de la información 
documental que nos permitiría articular particularmente la implicación de cada oficio en dichas ceremonias. Ni siquiera nos es fácil poder determinar, con pruebas concluyentes, el grado de conflictividad que, todo parece indicar, subyace bajo la ordenada disposición de las cofradías en sus desfiles.

Por todo ello, este artículo ha de ser interpretado como una aproximación y como un intento. Aproximación al mundo artesanal de la Barcelona de finales de la Edad Media e intento de abordarlo a partir de aquellas huellas que deja su participación en las entradas reales celebradas en la ciudad.

Fecha de recepción del artículo: agosto 2006.

Fecha de aceptación y versión final: septiembre 2006. 